Portland State University

PDXScholar

\title{
Gender differences in conversational style : an experiment in interpersonal communication
}

\author{
Constance M. Cooper
}

Portland State University

Follow this and additional works at: https://pdxscholar.library.pdx.edu/open_access_etds

Part of the Gender, Race, Sexuality, and Ethnicity in Communication Commons, and the Interpersonal and Small Group Communication Commons

Let us know how access to this document benefits you.

\section{Recommended Citation}

Cooper, Constance M., "Gender differences in conversational style : an experiment in interpersonal communication" (1992). Dissertations and Theses. Paper 4212.

https://doi.org/10.15760/etd.6096

This Thesis is brought to you for free and open access. It has been accepted for inclusion in Dissertations and Theses by an authorized administrator of PDXScholar. Please contact us if we can make this document more accessible: pdxscholar@pdx.edu. 
AN ABSTRACT OF THE THESIS OF Constance M. Cooper for the Master of Science in Sociology presented May 11, 1992.

Title: Gender Differences in Conversational style: An Experiment in Interpersonal Communication.

APPROVED BY THE MEMBERS OF THE THESIS COMMITTEE:
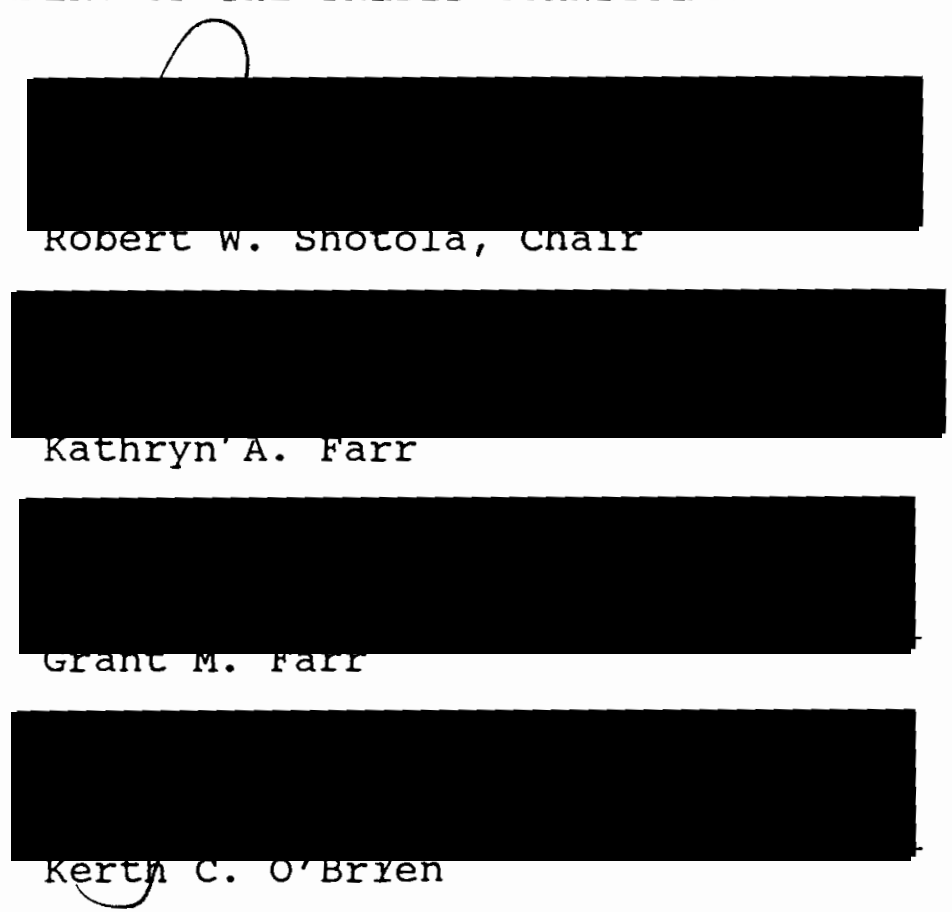

Communication problems and conflict may occur between partners in intimate dyads when systematic gender differences in language contribute to misinterpretations. This research investigated effects of gender on interpretations of hypothetical conversations between dyads, and also on judgements of likelihood of conflict. 
Following research by Fishman (1983), it was hypothesized that male and female subjects' interpretations. of male speakers would be more similar than would male and female subjects' interpretations of female speakers. Based on Tannen's (1990) work, it was hypothesized that male subjects' ratings of likelihood of conflict would relate to their interpretations of speakers as "controlling;" female subjects' ratings of likelihood of conflict were expected to relate to their interpretations of speakers as "rejecting." An experiment using a $2 \times 2 \times 2$ factorial design was conducted. Independent variables were: gender of an initiating speaker (speaker A), gender of the responding speaker (speaker B), and gender of the subject.) Dependent variables were subjects' ratings of five possible interpretations for each speaker, and subjects' ratings of likelihood of conflict between the speakers.

Stimulus materials were booklets of four hypothetical scenarios in which dyads had brief conversations. 'Speakers' genders were systematically rotated, so that each subject rated a conversation between each possible combination of genders (female $A$ to female $B$, male $A$ to male $B$, female $A$ to male $B$, male $A$ to female B). Dependent variables, rotated across scenarios, were rated on 6-point Likert-type scales. Booklets were administered to 216 undergraduate subjects.

The first hypothesis was supported by four significant two-way interactions obtained from 3-way ANOVAs conducted 
for forty dependent variables. Male and female subjects' interpretations of male speakers were similar, while male and female subjects rated female speakers differently.

The second hypothesis was first tested with 3-way ANOVAs. Two main effects, two two-way interactions and one three-way interaction were obtained. All showed significant effects of the gender of the initiating speaker on subjects' ratings of likelihood that conflict would follow the conversation. When a female hypothetical speaker initiated a conversation, conflict was rated as more likely than when a male speaker initiated the identical interaction.

The second hypothesis was further investigated with stepwise multiple regression analyses, using all variables as predictors. The hypothesis was supported by finding that different interpretations were associated with male and female subjects' ratings of potential conflict. Male subjects' ratings of conflict were related most strongly to control-aspects of interpretations of conversation. Female subjects' ratings of conflict were related to some of those same control-aspects, but also to rejected affiliation attempts.

Additional findings with ANOVAs suggested other types of gender variation between subjects and also between speakers. Further studies to investigate effects of conversation style and setting, as well as effects of gender, are suggested. 
GENDER DIFFERENCES IN CONVERSATIONAL STYLE:

AN EXPERIMENT IN INTERPERSONAL COMMUNICATION

by

CONSTANCE M. COOPER

A thesis submitted in partial fulfillment of the requirements for the degree of

\author{
MASTER OF SCIENCE \\ in \\ SOCIOLOGY
}

Portland State University

1992 
TO THE OFFICE OF GRADUATE STUDIES:

The members of the committee approve the thesis of Constance M. Cooper presented May 11, 1992 .

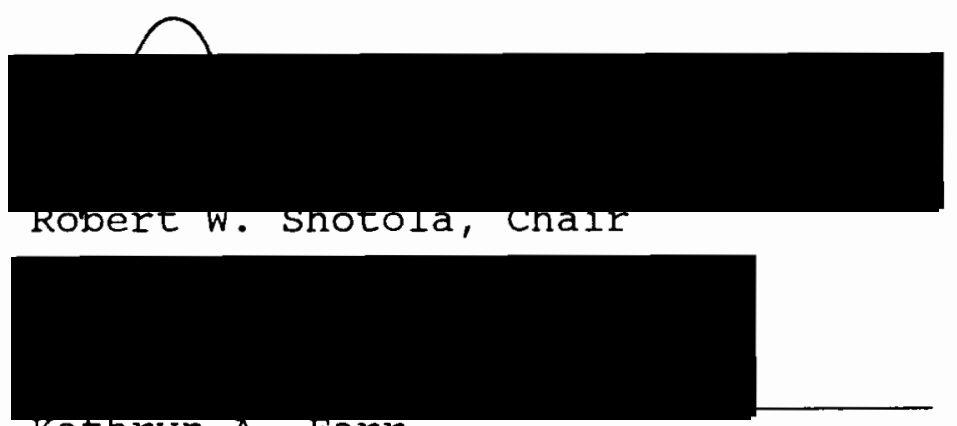

Kathryn A. Farr

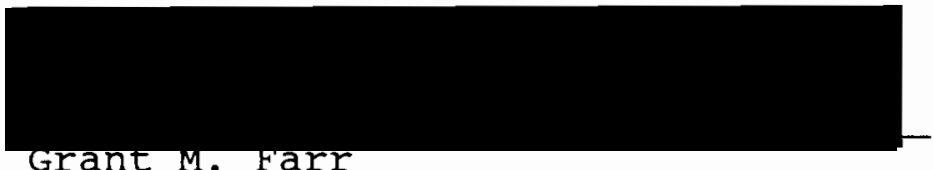

Grant M. Farr

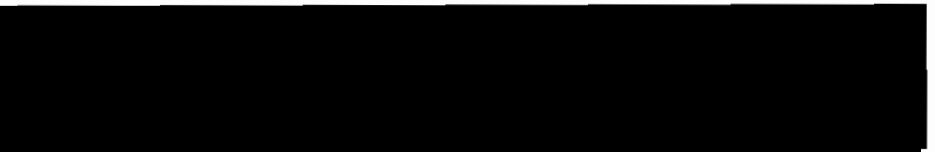

Kexty C. O'Brien

\section{APPROVED :}

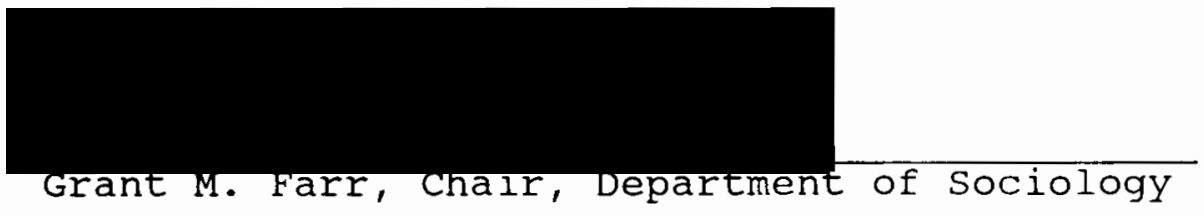

c. William savery, vice proyest for Graduate studies and Research 
TABLE OF CONTENTS

PAGE

LIST OF TABLES • • • • • • • • • • • • • • • • • • • v LIST OF FIGURES . . . . . . . . . . . . . . . . vii

CHAPTER

I

INTRODUCTION • • • • • • • • • . . . . 1

II

THEORETICAL BACKGROUND . . . . . . 6

Dimensions of Language . . . . . 7

Linguistic Features

Production of Speech

Interpretation of speech

Three Explanatory Perspectives • 23

Display: Situated Performance

Domain: Cultural Relativism

Domination: Politics and Power

Chapter Summary . . . . . . . 42

III

METHODOLOGY . . . . . . . . . . . 43

Research Design ...... . . 44

Stimulus Materials . . . . . 45

Procedure ......... . 48

IV

RESULTS . . . . . . . . . 51

Hypothesis 1 . . . . . . . . 54

Summary for Hypothesis 1 
Hypothesis 2 . . . . . . . 58

Analysis of Variance

Means Tables

Multiple Regression Analysis

Summary for Hypothesis 2

Additional Findings . . . . . 70

Summary for Additional Findings

$\mathrm{V}$

DISCUSSION AND CONCLUSTONS . . . . 76

REFERENCES

APPENDICES

A

SAMPLE STIMULUS BOOKLET • • . . . . . 92

B

SPEAKERS' NAMES FOR STIMULUS BOOKLET . 99 


\section{LIST OF TABLES}

TABLE

PAGE

I Mean overall Ratings All Variables . . . 52

II Mean Overall Ratings by Subject Sex . . . 54

III Two-way Interaction in Scenario 1

Illicit Demand by Speaker A

by subject sex . . . . . . . . 55

IV Two-way Interaction in Scenario 2

Consensus by Speaker A

by Subject Sex . . . . . . . 56

$\mathrm{V}$ Two-way Interaction in Scenario 1

Rebuff by speaker B by subject sex . 57

VI Two-way Interaction in Scenario 1 Direct Interpretation for

Speaker B by subject Sex . . . . . 58

VII Main Effect in Scenario 2 for Potential

Conflict and sex of

Initiating Speaker. . . . . . 60

VIII Main Effect in Scenario 4 for Potential

conflict and Sex of

Initiating Speaker . . . . . . 60

IX Two-way Interaction in Scenario 2

Potential conflict and speaker Sex. 61

$X$ Two-way Interaction in Scenario 3

Potential conflict and speaker sex . 61

XI Three-way Interaction in Scenario 2

Potential Conflict by Speaker

sex and by subject sex . . . . . 62

XII Predictors for Conflict in Scenario 1. . 66

XIII Predictors for conflict in Scenario 2. . 66

XIV Predictors for Conflict in Scenario 3 . . 67 
XV Predictors for Conflict in Scenario 4. . 67

XVI Main Effect in Scenario 1 Consensus-Building . . . . . . . 72

XVII Main Effect in Scenario 3 Consensus-Building . . . . . . . 72

XVIII Main Effect in Scenario 3 Rebuff by Speaker B . . . . . . . 73

XIX Main Effect in Scenario 4 Rebuff by Speaker B... . . . . 73

$\mathrm{XX}$ Main Effect in Scenario 4 Demand by Speaker A. . . . . . . 74

XXI Two-way Interaction in Scenario 4 Rebuff by Speaker B... . . . . 74

XXII Main Effect in Scenario 1 Direct Interpretation . . . . . 75

XXIII Two-way Interaction in scenario 2 Criticism by speaker A . . . . . 75 


\section{LIST OF FIGURES}

FIGURE

PAGE

1 Relationship Between Categories of Linguistic Properties

(Lakoff 1990, p. 28) . . . . . 9

2 Sex-preferential Vocabulary Usage

(Key 1975, p. 34). • . . . . 16

3 Text of scenarios in stimulus

Material . . . . . . . . 47 
CHAPTER I

\section{INTRODUCTION}

The thing that has always been hardest for Carla about living with Greg is how little he says. For her the words just keep coming. She dreams in sentences, paragraphs, and when she wakes up she wants to analyze the dreams. Over breakfast she likes to talk about what happened yesterday, and not simply what appeared to happen, but what was going on under the surface, and what will happen today.... But if she were to type up a transcript of everything Greg said on a particular day, (as she has pointed out to him many times), it would probably be about one page, double-spaced (Maynard 1981, p. 173).

Ace didn't see what he could do but try and reason with her.... He hoped Evey wouldn't say anything that couldn't be forgotten. What women didn't seem to realize was that there were things you know but shouldn't say (Updike 1959, p. 22).

Carla's problem with Greg, and Ace's concern about Evey, are "social evidence" (Coser 1972) for the ideas explored in this research: that speakers of a language may systematically use variations of it; that some of these differences in language are related to gender; and that misinterpretations and/or conflict may be caused by these differences.

There are two basic aims in tracing gender differences in language: (1) theoretical considerations- such as looking at language as it links micro-variables to macro-concepts 
(Cicourel 1981), or as it perpetuates inequality within "micropolitical structures" (Thorne and Henley 1975); and (2) practical applications- such as showing the extent to which a given interaction problem may seem to be "personal trouble" to those involved, but actually derive from a "public issue" (Mills 1959), or contributing knowledge useful in preventing "communication blockages" which impair intimate relationships (Turner 1970).

According to Berger and Luckmann (1966), "the most important vehicle of reality-maintenance is conversation." Collins (1981) advocates research to look at "the mechanisms by which long-term and large-scale social processes are reproduced in micro-situations;" Cicourel (1981) recommends the examination of conversation differences as they relate to statuses such as gender, age, ethnicity, etc., because "everyday encounters are an integral part of any discussion of macro-structures."

A depiction of this linkage between institutional

and interactional levels is given graphically by Goffman:

The expression of subordination and domination through this swarm of situational means is more than a mere tracing or symbol or ritualistic affirmation of the social hierarchy. These expressions considerably constitute the hierarchy; they are the shadow and the substance $(1976$, p. 6).

Language is an aspect of ongoing interaction in which power and hierarchies are constructed and maintained (Fishman 1983); social reality, a structural force created to 
legitimize gender relationships, is reproduced by "asymmetry in face-to-face interaction" (West and zimmerman 1987).

It has been suggested that because women and men tend to have different sets of life-experiences, they do not share knowledge completely, and that the power of men as a group allows them to make "authoritative value-judgements" in situations (Cameron 1985). This view echoes Berger and Luckmann's (1966) assertion that the confrontation of opposing "symbolic universes" implies a power struggle in determining whose "definitions of reality" will prevail.

Several perspectives have been used in the analysis of gender differences in language: (1) dramaturgical (West and Zimmerman 1987), or, as Thorne and Henley (1975) say, "the social elaboration of gender"; (2) subcultural (Cameron 1985); (3) cross-cultural (Tannen 1990); (4) biological (Lewis 1976); (5) functional (Smith 1985); (6) political (Cameron 1985), or, "the structure of male dominance" (Thorne and Henley 1975). Three of these viewpoints are considered in this paper: dramaturgical, cross-cultural, and political.

Cicourel's (1981) emphasis on the importance of everyday encounters as demonstrations of "the social competence necessary for membership in a group or culture;" is intriguing in relation to west and Zimmerman's (1987) dramaturgical viewpoint. Tannen (1990) suggests use of the "cross-cultural" approach, contending that there may be a 
misleading appearance of male dominance even when women and men relate as equals. Cameron (1985) cautions against research based on "sexist ideology" in which men are seen to be the norm and women are presumed to be deviant-from or inferior-to that male standard; she recommends feminist research, using a political perspective, to demonstrate patriarchal power. ${ }^{1}$

On the practical level of assessing gender differences in language, this paper is concerned with misunderstandings between cross-sex intimate dyads, and their potential to create conflict. Crosby, Jose and Wong-McCarthy (1981) note that "one extremely promising line of research is to look at miscommunication in cross-gender encounters" because the differences in female and male "conversational behaviors" may result in misinterpretations. Misunderstandings affect individuals and their relationships; they are communication failures which may generate conflict (McClintock 1983), so it is important to understand how they happen (Holtgraves 1991) •

Conversation between the two members of a dyad may be "the prototypical case of social interaction," other types of communication being derivations of that face-to-face situation (Berger and Luckmann 1966). Close relationships

${ }^{1}$ These three viewpoints correspond, in general, to the dramaturgical aspect of symbolic interactionism, the ethnomethodological analysis of interaction, and to conflict theory; they overlap in this presentation, so are not identified according to these classic sociological theories. 
are defined and negotiated by the interactants, even within institutions such as marriage (stewart, cooper and Friedley 1986); in these ongoing interactions, "in which reality is crystallized," inequalities may exist (Fishman 1983). Interactions between intimate dyads, such as friends, siblings, spouses, lovers, etc., have "the potential to be the most and least pleasant of all situations," precisely because closely bonded pairs may experience the most serious conflict (Wilmot 1987). In Kelley et al. (1978), heterosexual conflict is described as a "high-priority" research problem, because of its effects on families. Peterson (1983) points out that frequent conflict in a relationship expected to last a lifetime may be especially disturbing for the interactants. Bolton concludes:

In short, the development of love relations is problematic because the product bears the stamp of what goes on between the couple, as well as of what they are as individuals (Bolton 1980).

This paper presents an experimental investigation of some effects of gender on interpretations of everyday-type conversations. Theoretical and empirical literature from the fields of sociology, anthropology, and linguistics, relevant to the study of the social construction of gender and gender-related communication variation, provides background for the research. 


\section{CHAPTER II}

THEORETICAL BACKGROUND

The development of abstract, macro-level theory about gender differences in language, or the study of concrete, micro-level, practical aspects of those differences, requires some understanding of two general areas: the observable features of language, and the explanatory theories about them. These are the "what" and the "why" levels of analysis, presented in that order in this chapter.

The first section outlines the basic dimensions used to study language, beginning with a description of linguistic features and concepts. A review of literature follows, separated into two parts so that research on the production of speech is shown as being distinct from investigations into the interpretation of speech.

The second section reviews literature from three major theoretical bases of explanation for gender differences in language: "display," focusing on the dramaturgical construction and elaboration of social behavior; "domain," which looks at variation in beliefs and behaviors across cultures; and "domination," the political perspective, in which power is considered to be the crucial element in explaining differences between social groups. 


\section{DIMEISSIONS OF LANGUAGE}

To analyze "what happens" when people communicate, it is useful to summarize basic concepts in linguistics, using three categories of language features: those which may be studied as variables per se; those which relate to the production of speech; and those relating to interpretation of speech. All these features may vary between groups of speakers of a language (Thorne and Henley 1975).

\section{Linguistic Features}

But she was not listening to his words; she was reading his thoughts from his face. She could not guess that the expression of his face arose from the first idea that occurred to Vronsky-- that a duel was inevitable. The idea of a duel never entered her head and she, therefore, explained that fleeting expression in a different way (Tolstoy 1961 [1877], p. 322).

Language may be considered in its broadest sense, as "metalanguage" (Adler 1978), divided into two categories: verbal and nonverbal. It has been estimated that only about 7 percent of a communication message is given verbally, while the other 93 percent is conveyed nonverbally; it may be that the literal "content message" is carried on the "verbal channel," and the subjective "relational message," revealing the speaker's feelings, is carried on the "nonverbal channel" (Stewart, Cooper and Friedley 1986).

Nonverbal Language. Communication which occurs without the use of words can be divided into two types: interactive 
and non-interactive (Arliss 1991). The interactive category includes "proxemics"- a speaker's use of space (social distance) in relationship to a listener, and "haptics"- the use of various kinds of touch. The non-interactive category includes "paralanguage"- e.g., vocal qualities of pitch and inflection, and vocalizations such as sighs or laughter; and "kinesics"- e.g., eye contact, gestures, posture and facial expressions. Nonverbal communication may be more difficult to control and more likely to "leak" affect (Brown 1986).

Verbal Lanquage. Five basic functions of communication are identified by stewart, Cooper and Friedley (1986):

(1) Informing: giving/receiving information; asking questions; naming things; acknowledging.

(2) Controlling: persuading and being persuaded; threats and warnings; rejecting; bargaining; arguing.

(3) Imagining: fantasizing; role-playing; rehearsing.

(4) Feeling: expressing or responding to feelings; commiserating; blaming.

(5) Ritualizing: facilitating and maintaining social relationships; greeting; taking turns in conversations; social amenities.

The philosopher wittgenstein's similar list of functions added activities such as "joke-telling" (Black 1968).

Lakoff (1990) points out that ordinary talk is only one example of verbal communication among such "discourse genres" such as lecturing/teaching, writing, legal or religious ritual exchanges, and psychotherapy.

The properties of language can be categorized as "form" (words are connected to other words), "semantics" (words are 
connected to things), or "pragmatics" (words are connected to speakers.) (See Figure 1.) Within the category of "form" category of "form" are such features as morphology (word construction), syntax (word combinations), lexicon (word choice) and phonology (pronunciation) (Key 1975).

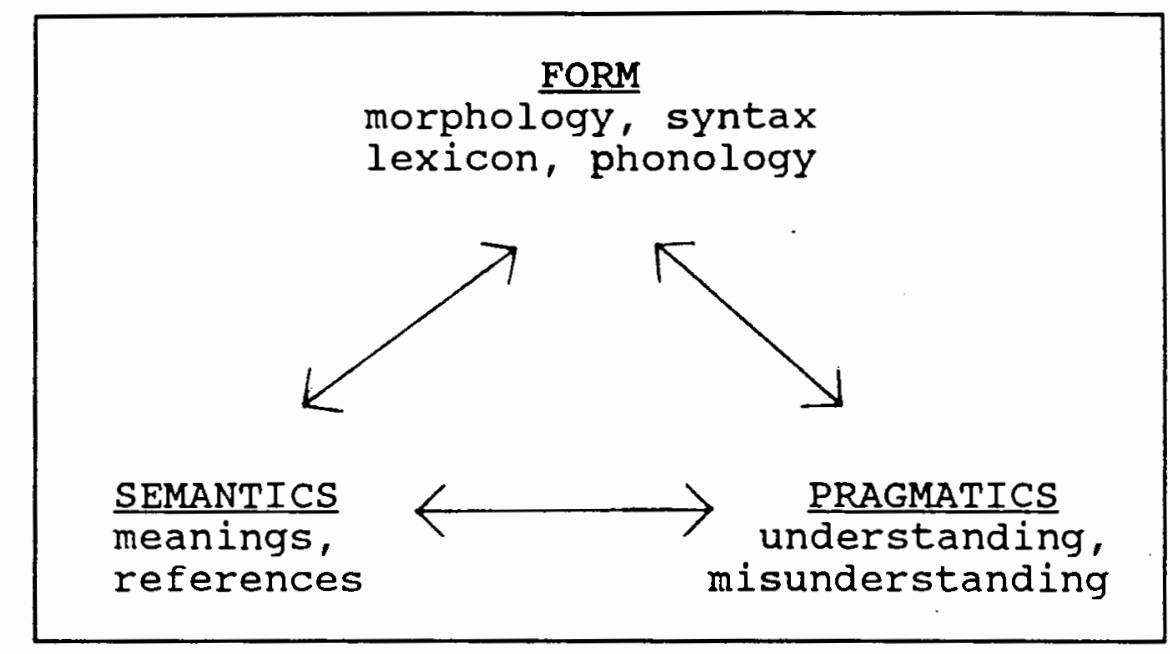

Figure 1. Relationship between categories of linguistic properties (Lakoff 1990, p. 28).

The analysis of gender-related differences in language does not generally include the tradition of assigning gender to inanimate objects (Adler 1978), nor the use of gender in pronouns (Cameron 1985). Feminist research is concerned with sexism found in such constructions as "the man in the street," and in feminine agentives denoting the female as other-than-normal ("authoress" vs. "author," etc.) (Henley and Thorne 1975); these concerns are not addressed extensively in this study, but could be examined in relation to the structure of language. 
One approach to the study of language structure is "sociocultural linguistics," which includes anthropological research based on the Sapir-Whorf hypothesis (Cameron 1985). According to the Sapir-Whorf hypothesis, languages are: (1) relativistic, in that reality is perceived differently by various social groups, and (2) deterministic, in that language itself creates varying perceptions of reality among speakers (Cameron 1985). Edward Sapir says: "The worlds in which different societies live are different worlds, not the same world with different labels attached" (Cameron 1985). Benjamin whorf comments on determinism:

...the world is presented in a kaleidoscope flux of impressions which has to be organized in our minds-- and this means largely by the linguistic system in our minds. We cut nature up, organize it into concepts, and ascribe significance as we do, largely because we are parties to an agreement to organize it in this way.... (Black 1968, p. 92 ).

It is argued that there is insufficient evidence for the Sapir/Whorf hypothesis (Brown 1986). It is also argued that language is a social resource controlled by powerful groups in a deterministic manner to create realities beneficial to them (Cameron 1985), and that meanings lost in translations are evidence for relativism (Black 1968).

The connection between the individual's mental structure of language, and the social group's shared use of language, exemplifies the intersection of the micro- and macro- levels of sociological analysis; this difficult 
question of direction of influence in the thought-language relationship, a challenge to investigate empirically, has also been considered by philosophers (Black 1968).

\title{
Production of Speech
}

\author{
"You like words like damn and hell now, \\ don't you?" \\ I said I reckoned so. \\ "Well, I don't," said Uncle Jack, "not \\ unless there's extreme provocation connected \\ with 'em. I'll be here a week, and I don't \\ want to hear any words like that while I'm \\ here. Scout, you'll get in big trouble if you \\ go around saying things like that. You want \\ to grow up to be a lady, don't you?" \\ (Lee 1960, p. 84).
}

The language produced by a speaker, and the vocabulary permitted/prohibited for that speaker, can vary by four gender conditions (Key 1975):

(1) sex of the speaker

(2) sex of the spoken-to (listener)

(3) sex of the spoken-about (referred-to)

(4) sex of the spoken-for (audience)

Considering only the speaker and the listener, speech can vary four ways: female to male or female, male to male or female (Bodine 1975)..$^{2}$ These differences are characterized by Birdwhistell (1970) as "intragender communication" (samesex) or "intergender communication" (cross-sex); Kramer (1974) adopts the term "genderlect" for the variation. Variation across cultures. In 393 B.C., Aristophanes acknowledged gender-related speech variation, by writing a conditions, there would be sixteen speech variations. 
play in which a female fails in her disguise as a man when she inadvertently speaks like a woman (Gregerson 1979). By the nineteenth century, sex differences in speech were noted by researchers among Brazilian and Caribbean Indians, as well as among Europeans (Adler 1978, Bodine 1975). Speakers in some cultures claim not to know of gender-related speech differences, and may misquote cross-sex characters during storytelling by using their own gender's speech style; in other cultures, speakers can coherently describe the gender differentiation in their language, children are taught to use the appropriate gender style, and cross-sex characters are quoted accurately during storytelling (Bodine 1975). Around the world, a variety of gender-related speech differences are found. Zulu women may not speak their father-in-laws' names, nor words that sound like them (Smith 1985); adults speaking Luo in Kenya use more imperatives with girls than with boys (Key 1975). Male students in Indonesia speak "Djakarta slang" not used by women, nor in their presence, and Turkish boys use ritual insults kept secret from females (Adler 1978). The Kurux language in India contains four forms of verbs, varying by both the sex of the speaker and the listener (Key 1975); Thai men and women emphasize verbs differently (Smith 1985). The Cham language in Vietnam has words containing an " $r$ " when spoken by a male, but a "y" in female speech (Key 1975). In Madagascar, men consider their speech to be more skillful 
because women openly show anger when they speak (but a man will make use of a woman's emotional language by having her confront someone he is angry with) (Adler 1978). Japanese contains words usable by either sex, as well as words with forms restricted for use by gender (Adler 1978). In China's Hunan Province, an ancient women's language has been kept alive by women using it while weaving, so that songs, poems, and biographies have been preserved along with it (Warner 1989). In Mexico, the Mazateco tribe's males use a language of whistles, understood but never used by women (Adler 1978); Creek Indian women in Oklahoma carefully maintain silence during public rituals (Bell 1990). The Koasati Indian language in Louisiana had varying verb forms for men and women, but in the 1940's a researcher saw the young women of the tribe beginning to use the men's language (Adler 1978). The Lakota Sioux also had gender-specific speech, lost by the imposition of English (Medicine 1987). Immigrants to America may make linguistic choices that vary by gender. Zentella (1987) cites the Puerto Ricans' dilemma of being multilingual/bilingual/monolingual in Castilian Spanish, dialects of Puerto Rican Spanish, white English, and Black English. Adler (1978) says that among Eastern European Jewish immigrants, Hebrew became known as "papa's language," while Yiddish was "mama's language." Intra-cultural variables. Gender differences in language were often overlooked in the past (Bodine 1975). 
When Key (1975) studied the Ignaciano Indians in Bolivia, the preliminary field notes by another ethnographer had completely missed the gender variations in the language; it may be even more difficult to see the differences in our own language (Kramer 1974). Western societies have been assumed to be "linguistically androgynous" (Thorne and Henley 1975); e.g., it has been said that women do not produce or use slang, but it may be that women's slang has been hidden from, or ignored by, male researchers (Baron 1986). The women's movement was a turning point in linguistics, marking a shift in "scientific paradigm" in the direction of gender differentiation (Thorne and Henley 1975).

While variables such as age, SES and/or ethnicity may be better predictors than gender for language use (Smith 1985), analysis is complicated by such interrelated variables as the tendency for men in class-stratified societies to use more "stigmatized variants" (lower-class forms of speech) than women use (Philips, steele and Tanz 1987). Gender differentiation may also vary between rural and urban areas, as was shown by Bedouin men (who spent more time in contact with women) speaking more like women than did urban Arab men, though all men tried to avoid the use of women's speech styles (Adler 1978).

Analyses of language differences can take into account variation occurring across time (i.e., Elizabethan vs. contemporary English), and regional dialects (i.e., Canadian 
vs. Australian English) (Key 1975). Distinct variation may be found in subcultural argot/group slang (Brown 1986), in occupational vocabularies (Key 1975), and in the special "registers" used for speaking to babies, sick people, pets, plants, etc. (Brown 1986). These differences contribute to the variation of speech, in addition to the effects of gender; they may also vary by gender, so again, problems in language analysis include interactions of variables with complex directions of influence.

Gender-related variables. While "exotic" languages tend to use "sex-exclusive differentiation"- an easily observed set of different, gender-specific, rules for use of vocabulary, pronunciation, etc., European languages use "sex-preferential differentiation"- a more subtle distinction based on varying, gender-related, rates of usage of the same vocabulary, etc. (Bodine 1975). For example, it was observed in 1907 that men and women were using the same words with varying connotations, so that only women would use the word "common" to mean "vulgar" (Adler 1978).

A gender difference is seen in the choice of words for colors, such as "ecru," "beige," "mauve" and "fuschia:" men may tend to view these fine distinctions as effeminate, and choose broader color groups such as "gray," or "red" instead (Eakins and Eakins 1978). In writing, it has been noted that women underline words for emphasis more often than men tend to use this expressive device (Baron 1986). 
Key (1975) charts the variables in sex-preferential use of vocabulary. (See Figure 2.) Her diagram would

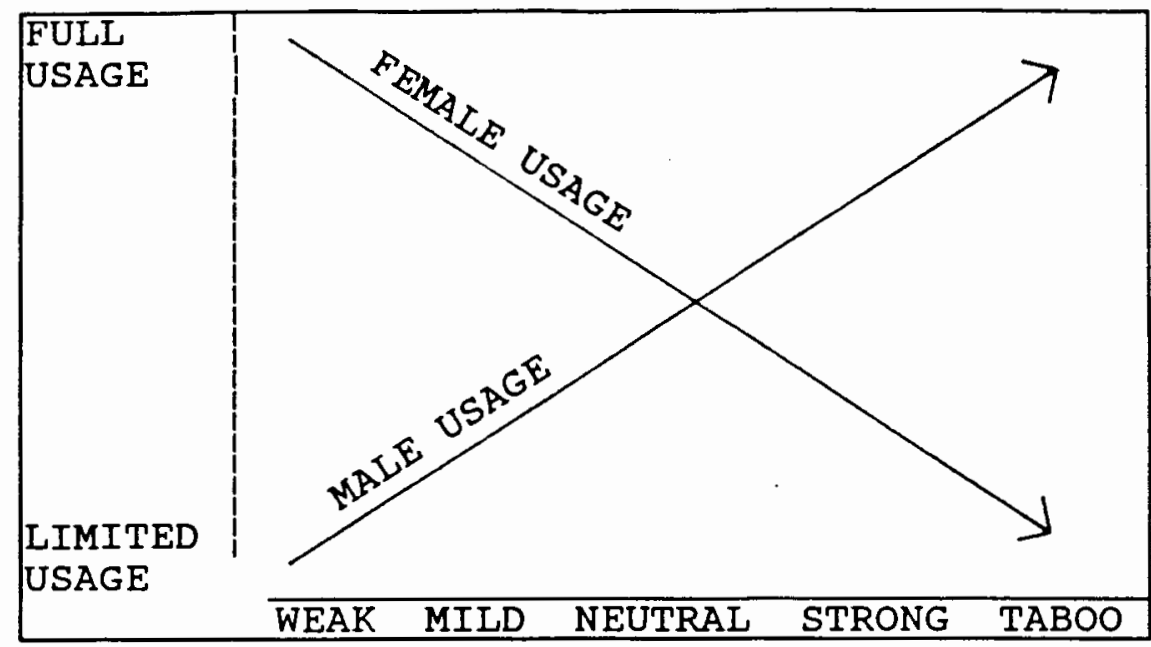

Figure 2. Sex-preferential vocabulary usage (Key 1975, p. 34).

include, at the left side, words such as "pretty," "precious," "cute," and "oh, dear." At the right side, strong terms would include "belly," "guts," and on into taboo obscenities. A man using the left side of the chart is considered effeminate; a woman using the right-hand side of the chart is considered coarse (Key 1975).

Over one hundred inter-gender and intra-gender differentiating variables have been identified for contemporary English including form, such as the use of interruptions (Arliss 1991) and content, such as the use of euphemisms (Baron 1986). These differences are a matter of degree: they may vary only slightly or may vary almost exclusively by/with/about/for gender. 
Empirical research. Several studies have investigated gender variation in the production of speech. An experiment analyzing verbal descriptions of a stimulus object found men making more objective observations, and women making more emotional/subjective comments. Men produced longer descriptions if given no time limit, and men talked more after being instructed that they had "failed" in a prior descriptive attempt (Eakins and Eakins 1978).

In conversation with dyads, differences were found between cross-sex and same-sex dyads. In cross-sex situations, males used fewer qualifiers (i.e., "sort of" and "maybe"), while women used more of them; but when speaking with the same sex, men and women used equal numbers of qualifiers (Stewart, Cooper and Friedley 1986). Carli (1990) found that women used more "tentative" Ianguage in cross-sex dyads, but not when conversing with other females; women used more intensifiers (i.e., "so" and "quite") and more reinforcers (i.e., "m-hm," and "I see") when talking to other women than when speaking with men. If visibility to a conversational partner was the experimental variable, men increased their amount of speech by $40 \%$ while invisible to their partner, but women decreased their speech by $40 \%$ if they were not visible while speaking (Argyle, Lalljee and Cook, 1968).

A study of parent-child interactions found fathers interrupting children more often than mothers interrupted 
them; either parent more likely to interrupt a daughter than a son; and boys somewhat more likely to interrupt a parent than were girls (Greif, 1980). Zimmerman and west (1975) found that women in cross-sex conversations were silent more often than men, and that a woman's silence tended to follow an interruption, a speech-overlap, or a "delayed minimal response" by her male partner. (A "delayed minimal response" is a period of silence, then a brief comment such as "oh.") Fishman (1983) used content analysis to analyze intimate dyads' cross-sex conversations, finding that women asked more questions than men, and made more attempts to raise new conversational topics.

Spencer and Drass (1989) studied "conversational power" in same-sex dyads, defined as the use of "verbal strategies" to promote a speaker's self-definition. Speakers of either sex who identified themselves as "malelike" made more challenging statements. Assertive statements were responses to assertiveness by a conversation partner; the authors see competitiveness as an emergent quality. In contrast, when crosby, Jose and Wong-McCarthy (1981) tried to find variation in assertiveness related to gender-identity, they found little difference between males and females. They found gender per se to be a better predictor of variation than the self-concept of androgyny. It may be that some variables which are hypothesized to vary by gender only vary in relation to region, SES, etc., 
or do not actually vary, or are inadequately defined as variables. DuBois and Crouch (1974) tested Lakoff's intuitive observation that women use more "tag questions" (ending sentences with questions such as "..., isn't it?" as non-committal, approval-seeking devices). They did not find that women use more of these constructions, concluding that men may also use "tag questions," and that some of those questions may reflect confidence, rather than uncertainty.

\section{Interpretation of Speech}

The end of these discourses was that one night during which she had shown every sign of unusual excitement, Mrs. Sinico caught up his hand passionately and pressed it to her cheek. Mr. Duffy was very much surprised. Her interpretation of his words disillusioned him (Joyce 1962 [1916], p. 111).

The "passive" process of language comprehension varies by gender, but separately from the differences found in the "active" production of speech (Lakoff 1990). Sex-exclusive forms spoken in languages such as Japanese and the Caribbean Arawak are comprehended by both genders; in contrast, the overlapping sex-preferential usage in English creates subtle variation, too covert for comprehension difficulties to be recognized as being gender-related (Lakoff 1990).

Lakoff says:

...both sexes use the same words in the same constructions, but understand them differently.... This misunderstanding is serious: we think we understand and have been understood, when we really don't and haven't (1990, p. 201). 
Types of misinterpretation. There are two general ways a misunderstanding can occur (McClintock 1983):

(1) Mismapping- events are "mapped into different categories" by interactants who possess the same cognitive categories;

(2) Mismatching- events are categorized differently by interactants whose cognitive categories per se are different.

Lakoff (1990) says that interactants see other's behavior from their own perspective, asking themselves, "What would that mean if I did it?" A corresponding attitude is inferred from talk or actions: research shows these "internal attributions" being made even when a speaker has been arbitrarily assigned a position to argue (Brown 1986). It may be that men's attributions for women's speech are mismapped, if Lakoff (1990) is correct in saying that American women behave in "conventionalized" ways, but that men tend to misinterpret them by judging their behavior as being "real" rather than as being "convention." If that is the case, then it is an example of Brown's "correspondent inference."

Because gender is immediately identifiable, by clothing, voice, etc., Goffman says:

Right from the very start of an interaction, then, there is a bias in favor of formulating matters in sex-relevant terms.... This is not a small bias (1977, p. 319).

Turner (1970) cites "stereotypes" as one source of the "crystallized conceptions" used by an interactant to 
attribute a disagreement to the other's personality; he says that a personal-context attribution is a necessary condition for conflict to occur. Even in the absence of a personal relationship, interpretations can be made based on a presumed, stereotyped, "personality."

It seems that whether an interactant interprets the other's speech/behavior from the viewpoint of "What would it mean if I did that?" or makes an attribution from the perspective of "I know what it means when you do that," a mismapping/mismatching misinterpretation is possible.

Gender-related styles of communicating may contribute to misinterpretation, according to Lakoff (1990). She says that (in most cultures, when women speak indirectly, they use the style of "deference," in which statements are phrased as questions, uncomfortable topics are discussed in euphemisms, and the speaker's own ideas are "diluted" by hedging; men who speak indirectly, especially in western cultures, generally use the style of "distance," in which expressions of emotion are avoided, uncomfortable topics are expressed via technical terminology, and the speaker carefully avoids "invading" others' personal topics] Lakoff says that women and men may intend to be polite, but their use of different styles leads men to see women as being indecisive and) frivolous, while women see men as being cold and apathetic. other sources of misinterpretation are the multiple meanings of words, and the multiple ways of expressing 
ideas. Tannen and Lakoff extend conventional definitions of "synonym" and "homonym," classifying entire utterances in the category of "pragmatic" language (see Figure 1):

(1) Pragmatic synonyms- same meaning, different forms; e.g., "Would you like some tea?" and "How about a cup of tea?"

(2) Pragmatic homonyms- same form, different meanings; e.g., "That's a nice fountain pen" means "You have good taste," or "I want that pen for Christmas," etc. (Lakoff 1990).

Empirical research. Studies have been done to look at gender differences in interpretations. Stewart, Cooper and Friedley (1986) report that when speakers used disclaimers such as "I'm no expert, but...," women were perceived as uncertain and not influential, but men using the disclaimers were perceived as more polite and thoughtful. An experiment using hypothetical scenarios showed that men were judged as "better adjusted" when they did not disclose personal information, while women were judged as "better adjusted" when they did reveal personal problems (Derlega and Chaikin 1976) .

Carli (1990) reports varying levels of "influence" in an experiment: women were more influential with men when using "tentative" language, to the extent that the least influential condition was when a woman spoke assertively to a man; the highest level of influence was found when women spoke assertively to other women. Lowery, snyder and Denney (1976) presented subjects with hypothetical scenarios, 
finding that the most potential for aggression was perceived when two women were talking, but the least aggression was perceived when a woman spoke to a man.

The importance of interpretation, or perception, in the definition of a situation is cited by Peterson (1983): for situations most often mentioned by couples as causing conflict, such as "criticism," "rebuffs," and "illegitimate demands," Peterson notes that "the key condition" is how another person's behavior is interpreted or perceived. Differences in the definition of the situation can precipitate conflict, and may be related to gender variation in the use of language.

\section{THREE EXPLANATORY PERSPECTIVES}

This section reviews three theoretical explanations for gender-related language differences: (1) "Display"- a dramaturgical view of gender variation as reifying the "natural" social status of gender; (2) "Domain"- a "crosscultural" explanation; and (3) "Domination"- a political and power perspective. These derive, in general, from symbolic interactionism, ethnomethodology, and conflict theory.

\section{Display: Situated Performance}

So David stared up at the tall, toothless man and said, "It's sissy stuff. Like 'You and I went to the store." "He spoke in exaggerated accents, like Miss clapp. The men laughed. "Not, "You and me went fishin"" (Michener 1949 , p. 6). 
In the process of "cultural elaboration," gender differences are created and displayed, just as class distinctions are socially produced (Eakins and Eakins 1978). Gender is not an "ascribed" status, but is "achieved" by behaving according to gender norms. Rather than having a "gender identity," people work at "gender activity". (Fishman 1983).

Birdwhistell (1970) identifies three types of sex differences:

(1) Primary- at the level of physiology of sexual reproduction;

(2) Secondary- at the level of anatomical differentiation;

(3) Tertiary- "social-behavioral" and "situationally produced" differences.

He says the "tertiary" characteristics are used by humans (and probably by other "weakly dimorphic" species) for gender display and recognition, and are seen in movement, position and expression. ${ }^{3}$

West and Zimmerman (1987) argue that "gender" is a "master identity" continually and inescapably managed, aside from social roles a person may play. They classify gender variation according to a triad somewhat different from Birdwhistell's, with only one category based on biological differences: (1) sex-established by assignment into a category based on biology; (2) sex category- maintained by

${ }^{3}$ Birdwhistell cautions against seeing "gender display" as relevant only to sexuality, because it is used in context and has meaning for concepts such as the division of labor. 
"identificatory displays" appropriate to a category; (anyone can claim membership in either sex category); (3) Genderthe continual management of situated conduct, according to social norms for behavior within each sex category.

The process of creating sexual dimorphism is invisible, so gender differences are accepted as being "axiomatic" (Smith 1985). It is a socially learned belief that gender requires specific characteristics for males and females, and that these are opposites; it is accepted that whatever is "masculine" cannot be "feminine" (Eakins and Eakins 1978).

West and Zimmerman (1987) emphasize the need to investigate gender as "an ongoing activity embedded in everyday interaction: "while the categories of "male/female" may easily be seen, the members of these categories are always working at "doing" effective and convincing "masculine/feminine" gender performance. Gender identity provides a guide for making choices among "verbal strategies," affecting verbal style separately from the content of conversation, which is structured by social roles (Spencer and Drass 1989).

Lakoff (1990) points out that while regional dialects vary by words and pronunciation, gender differences are more often found in features such as intentions/interpretations, in the category of "pragmatics." Regional differences develop when speakers are isolated from other speakers of a language, but polarized sex differences are reinforced by 
speakers being integrated with each other (Lakoff 1990). A study by Haas (1979) supports Lakoff's hypothesis: her observation of children's "acquisition of genderlect" showed cross-sex interactions varying from same-sex interactions, leading Haas to say, "Roles become defined when individuals are with members of the opposite sex."

Brown (1986) reports findings which show how a display contributes to the production of a social fact: subjects randomly assigned to act as if they controlled information were rated by other subjects as actually possessing superior knowledge. An intentionally created performance was perceived as deriving from personal attributes, with subjects "underestimating the power of the situation" (Brown 1986). Berger and Luckmann say:

Through reification, the world of institutions appears to merge with the world of nature... The paradigmatic formula for this kind of reification is the statement "I have no choice in the matter, I have to act this way because of my position...." (Berger and Luckmann 1966, pp. 90, 91).

Goffman's contribution to the theory of gender as display is valuable:

Any scene, it appears, can be defined as an occasion for the depiction of gender difference, and in any scene a resource can be found for effecting this display.... Displays are part of what we think of as "expressive behavior," and as such tend to be conveyed and received as if they were somehow natural, deriving, like temperature and pulse, from the way people are and needful, therefore, of no social or historical analysis (Goffman 1976, pp. 3, 9). 
The situational enactment and elaboration of gender provides the material for the ongoing micro-level production of gender. This socially created macro-level reality of gender is, in turn, a social norm which constrains behavior. When women and men use language in different ways, they are displaying conformity to, and contributing to the construction of, the social fact of gender.

\section{Domain: Cultural Relativism}

"You're the one that's awful, steve. You really are. I'm trying to show you a glimpse of my heart, to tell you how it feels when you're gone.... You don't know what it's like for me here alone. You just don't know."

"Yes, I do," he said. "I know, Mimi.... You see, I don't know what to say, when you start talking about showing me a glimpse of your heart, and all that" (Parker 1944, p. 33).

The "cross-cultural" approach to gender differences in language sees men and women as socialized into two separate cultures. Communication is, therefore, cross-cultural (Tannen 1990). Theorists using this viewpoint do not show that males are dominant. They see men, socialized to be masculine, managing the "control-related aspects of interaction," and women, socialized to be feminine, managing "interaction in the pursuit of affiliative goals" (Smith 1985). Women's concern in interactions is "Do you like me?" but men's concern is "Do you respect me?" (Tannen 1990).

Berger and Luckmann's concept of "relevance structures" is useful in analyzing language as cross-cultural: 
My knowledge of everyday 1 ife is structured

in terms of relevances. Some of these are

determined by immediate pragmatic interests

of mine, others by my general situation in

society... (1966, p. 45).

Gender-differentiation as "cross-cultural." For Tannen (1990), communication is "a continual balancing act, juggling the conflicting needs for intimacy and independence." Women tend to focus on "intimacy," which requires being connected, being equal, and being in agreement; men are more concerned with "independence," which requires being separate, being superior, and possibly disagreeing. Tannen suggests that men live in a world centered on competition and contests for position within a hierarchy, so their conversations involve "a struggle to preserve independence and avoid failure," while women live in a world centered on community, and connections within a network, so their conversations involve "a struggle to preserve intimacy and avoid isolation" (Tannen 1990). When people perform well, there can be unintended consequences: a man may increase his status, but a woman sees his lack of intimacy; a woman may increase her appearance of being cooperative, but a man sees her lack of competence (Tannen 1990). As another example of an unintended consequence of this difference, Stewart, Cooper and Friedley (1986) say that when a woman intends to communicate protection and support for a man, he is likely to interpret her as trying to control him. 
Kelley and his colleagues (1978) found that males were perceived as conflict-avoidant while women were perceived as wanting to confront problems directly. This may seem paradoxical, but Goffman (1977) says that women are not "socialized into the fighting frame," so they escalate conflict in ways that men avoid; a man faced with a woman pressing an argument toward a fight may not know what to do about a breach of the "tacit contract" he takes for granted.

Some writers suggest that the two cultures experienced by men and women are based on styles of relating: the female socio-emotional style vs. the male task-oriented style (Carli 1990). This expressive vs. instrumental orientation explains varying interpretations of conversational reinforcers such as "uh-huh," "okay," and "I see"- females may interpret them to mean "I understand," males to interpret them as meaning "I agree," (Crosby, Jose and WongMcCarthy 1981). The "talking" vs. "doing" style accounts for variation in decision-making technique:

Women expect decisions to be discussed first and made by consensus. They appreciate the discussion itself as evidence of involvement and communication. But many men feel oppressed by lengthy discussions about what they see as minor decisions, and they feel hemmed in if they can't act without talking first. When women try to initiate a freewheeling discussion by asking, "What do you think?" men often think they are being asked to decide (Tannen 1990, p. 27).

The idea that there are two styles of relating also clarifies the differences in ways of comforting someone who 
is sad or upset- women listen and show concern, but men consider it appropriate to change the subject, thinking that diverting someone's attention is courteous (Stewart, cooper and Friedley 1986). Arliss (1991) says that cross-sex relationships are a "compromise" between the distance of male relationships and the closeness of female relationships.

Sociology of knowledge. For ethnomethodologists, "the everyday, taken-for-granted implicit rules people use in interacting with one another" constitute a social group's "stock of knowledge;" individuals accepted as competent group members are those "who share and demonstrate that stock of knowledge" (Chafetz 1988). Collins suggests that people use conversation "for checking out social alliances:"

...people tacitly recognize particular kinds of conversational practices as symbols of common memberships; and then social motivations come from the feelings of confidence or lack thereof which they get from these implicit tests of group belonging in various interactions (1981, p. 104).

Gender variation shows "different strategies for the creation of discourse coherence," and does not indicate male domination (Philips, steele and Tanz 1987).

Berger and Luckmann (1966) say that there is more "objective reality" available than is consciously perceived, because of the "social distribution of knowledge." Reality is defined according to familiarity with various facets of everyday life: 
... Ianguage constitutes both the most important content and the most important instrument of socialization.... It is language that must be internalized above all. With language, and by means of it, various motivational and interpretive schemes are internalized as institutionally defined.... (Berger and Luckmann 1966, p.135).

Cameron (1985) explains that the usual model of communication in western thought is "telementational," with language assumed to be a method of transferring an idea from a speaker's mind into the mind of a listener. She notes that such a process would only be possible if there were "a unique one-to-one correspondence between forms and meanings" in the interactants' minds.

Mcclintock (1983) notes that people often have "distinct dictionaries of categories that they use" when classifying events, and Berger and Luckmann (1966) say that the concept of "common language" varies from language used in primary groups, to regional or class dialects, to the level of a national community defined in terms of language. According to Berger and Luckmann (1966), acquisition of "role-specific" vocabulary, an aspect of secondary socialization, includes the internalization of emotional responses, interpretations, behaviors, and tacit understandings along with that vocabulary; knowledge varies by occupation, with the division of labor being a source of role-specific knowledge.

From an ethnomethodological viewpoint, people create shared understandings through conversation which follows the 
implicit rules for the "stock of knowledge" (Chafetz 1988). As Berger and Luckmann note, knowledge varies among people:

The social distribution of knowledge of certain elements of everyday reality can become highly complex and even confusing to the outsider $\left(1966\right.$, p. 46).$^{4}$

Interactants may assume they share more understanding than is actually the case (Cameron 1985). Miscommunication may result when gender-role specialization prevents a speaker from taking the role of the other (Turner 1970). collins (1981) contends that traditional micro-sociological theorists assumed that there is not a "fundamental problem in taking the role of the other;" he recommends that microsociology should be concerned with the ways that reality is situationally "filtered." Goffman (1981) says people use context-dependent "reinterpretation schemas" which may affect their reception of communication messages. Holtgraves (1991) questions the theoretical assumption that there is a "shared framework" for the interpretation of remarks made in various contexts, saying that in the absence of such a framework, a speaker's message is misinterpreted.

In a "cross-cultural" analysis, conflict between men and women can be seen as having two sources. (1) Genderrelated variation in socialization regarding expectations and goals for actions- "Occasions for conflict will increase

${ }^{4}$ Berger and Luckmann indicate some level of awareness, however primitive, regarding gender differences in language: "I know that 'woman-talk' is irrelevant to me as a man...." (1966, p. 45). 
to the extent that the goals of the participants are highly valued and incompatible" (Peterson 1983). (2) Variation in language socialization- when the gender differences in communication style are not recognized, women are treated according to norms for men, and men are misunderstood when they speak to women as they would talk to other men; "Their words don't work as they expected, or even spark resentment and anger" (Tannen 1990).

Domination: Politics and Power

But as soon as the guests said goodnight and what an awfully nice evening it had been, and the door closed behind them, there the Weldons were again, without a word to say to each other.

You'd think that you would get used to it, in seven years, would realize that that was the way it was, and let it go at that. You don't, though. A thing like that gets on your nerves. It isn't one of those cozy, companionable silences that people occasionally fall into together. It makes you feel as if you must do something about it, as if you weren't performing your duty. You have the feeling a hostess has when her party is going badly, when her guests sit in corners and refuse to mingle.

Mrs. Weldon casts about in her mind for a subject to offer her husband (Parker 1944, p. 263).

According to the "domination" perspective, gender variation in communication correlates with differences in power. Conversation is controlled, not merely by choice of topic, but also by "having control over the definition of the situation in general," including the choice of having a conversation at all (Fishman 1983). Zimmerman and West say: 
Interruptions, lapses in the flow of conversation, and inattentiveness are commonplace occurrences, seemingly far removed from sociological concerns with such things as institutionalized power.... these events may be related to the enduring problems of power and dominance in social life (1975, p. 105).

Lakoff (1975) characterizes "linguistic discrimination" as affecting women in two ways: (1) how women are taught to use language, and (2) how women are treated by language:

...language is politics, politics assigns power, power governs how people talk and how they are understood (1990, p. 7).

Conversational power. The results of an interaction may depend more on the unequal power, or the perceived inequality, of women and men than on features such as the exchange being public vs. private, task-oriented vs. instrumental, etc. (Scott 1980). It is argued that speakers who lack power or status use language differently than those who possess power/status, and that language variation only appears to be gender-related because it is women who are subordinate (Simkins-Bullock and Wildman 1991).

Social groups with different value systems may use language differently:

(1) High-ranking individuals' systememphases on individual achievement, independence, external evaluation, instrumental behavior, future-time orientation.

(2) Lower-status value system-emphases on group identity, harmony with others, importance of self-realization, present-time orientation (Eakins and Eakins 1978). 
Women seem to live by the lower-status value system, but Lakoff (1975) points out that counter-culture men, upperclass British men, and academic men use words such as "charming," "divine," etc., without being judged effeminate; the "low-status" value system may represent those who are "uninvolved/out of power/not working in the world."

The source of gender-related language variation may be male domination, in the same way that all basic social institutions are controlled by males (Eakins and Eakins 1978). Gender is "a powerful ideological device, "socially produced and accepted as an objective reality, necessary for a hierarchy in which men are dominant "by nature" and women "inevitably" defer to others (West and Zimmerman 1987). The deference of women "developed under physical and political domination" and is "identified as a defining characteristic of femininity" (Lakoff 1990).

Power is an emergent quality, negotiated during talk, but is also based on social statuses that interactants bring to the conversation (Spencer and Drass 1989). Goffman notes that interactional fields provide expressive resources:

...the management of talk will itself make available a swarm of events usable as signs.... the opportunity is available, often apparently unavoidably so, for someone to emerge as dominant.... gender differences are produced.... (1977, p. 325).

Kramarae and Jenkins (1987) categorize language as male "property," which feminists must "seize" to gain control of their lives. 
Power in use of language. Symbolically, conversational power is the ability to assert one's own definition of a situation or to challenge the other's definition; concrete power is found in actions such as interrupting, or in dominating speaking time (Spencer and Drass 1989).

Zimmerman and West (1975) found equal amounts of interrupting and overlapping speech in same-sex dyads, but in cross-sex dyads, $96 \%$ of interruptions and $100 \%$ of overlaps were by men. Despite the many interruptions of females by males in their study, no female reacted with a negative sanction. The only female to interrupt a male was a graduate teaching assistant who interrupted a male undergraduate twice- but he interrupted her eleven times.

Another study found that women with money or power were seldom interrupted, just as men are not generally interrupted (Stewart, Cooper and Friedley 1986), supporting the suggestion that so-called gender differences actually are related to power. Greif (1980) says that her findings on parents' interruptions of children provide evidence of the socialization of girls into a less-important status; she notes that children learn gender-appropriate behavior by using adults as models, so male-female language differences are perpetuated. Edwards, Honeycutt and Zagacki (1989) studied imaginary interactions, finding that women imagined themselves as talking more than their male conversational partners; the authors suggest that women imagine saying more 
than research indicates they actually get a chance to say in real life. It has been found that the African Barundi support social stratification by allowing higher-caste speakers to talk first, but "no such rule" is found in "our culture" (Speier 1973). It may be that a gender-related hierarchical rule actually does exist.

If interruptions and conversation-monopolizing provide evidence of male dominance, so do silences and delayed minimal responses. Ordinarily, a minimal response is a helpful device, used by a listener to unobtrusively encourage a speaker to talk, such as saying "mhmm" or "yeah" at appropriate pauses; however, such a response delayed one to ten seconds does not facilitate the conversation, and may show misunderstanding or boredom (Zimmerman and west 1975).$^{5}$ Eakins and Eakins (1978) say, "Most of us have experienced the disappointment of the dampening pause and the tardy response." Men's use of these delayed responses "inhibits" conversation with women, as their short answers violate turn-taking rules, and the conversation lags (stewart, Cooper and Friedley 1986). Fishman's (1983) study showed women initiating topics by saying "Do you know what?" or "This is interesting" twice as often as men, possibly in an

${ }^{5}$ There is confusion of terminology in the literature. stewart, Cooper and Friedley (1986) use the term "minimal response" to mean "delayed minimal response." Their term for a helpful response, called a "minimal response" by Zimmerman and West, is a "regulator." But Borisoff (1985) calls that a "filler," crosby et al. call it a "reinforcer," and Lakoff (1975) identifies it as a "back channel." 
effort to secure attention; women used the phrase "You know" five times as often as men, probably, Fishman says, as an attention-holding device. Men made twice as many statements as women, and women nearly always responded to them; women's statements did not elicit male responses at the same rate. Men used minimal responses, tending to terminate women's topics, while women continually reinforced men's interaction while the men were speaking. Women made $62 \%$ of the total attempts to raise topics of conversation, but made only $38 \%$ of the initiations of topics which actually became conversation material; the content of potential topics was too similar to explain the difference (Fishman 1983).

Fishman also found women in her study asking more than twice as many questions as the men; she suggests that if a woman phrases an idea as a statement, she is less likely to elicit a response from a man than if she formulates the idea as a question. She notes that questions are a linguistic device in the class of "paired relations," like greetings, which require answers. ${ }^{6}$

Goffman (1981) suggests another interaction variable, the "floor cue:" a laugh or little comment, less "intrusive" than an outright initiation of conversation, meant to make someone invite the speaker to continue; he says that wives probably attend to floor-cues more often than do husbands.

${ }^{6}$ Question-answer communication has a crucial "structure of obligation" which may be even more constraining than ritualized greetings (Speier 1973). 
Goffman recognizes the significance of power in

interactions, and how the effects of micro-level processes can accumulate to create macro-level forces:

However, routinely the question is that of whose opinion is voiced most frequently and most forcibly, who makes the minor ongoing decisions apparently required for coordination of any joint activity, and whose passing concerns are given the most weight. And however trivial some of these little gains and losses may appear to be, by summing them all up across all the social situations in which they occur, one can see that their total effect is enormous (Goffman 1976, p. 6).

In agreement with this explanation by Goffman, Fishman says that men define reality by making the choices about conversation. Fishman concludes that women do more actual work than men in conversations; she says that failures of women in interaction are due to men's failure to do as much of the work, and that men's successes are because of women's greater efforts in interactions. She says:

Women are the "shitworkers" of routine interaction, and the "goods" being made are not only interactions, but, through them, realities (Fishman 1983, p. 99).

Discrimination by language. Lakoff (1975) says that girls are socialized not to "talk rough" like boys, but then, women are discriminated against for being unable to speak precisely or assertively; she sees a woman as having the difficult choice of speaking so she is either "less than a woman or less than a person." Similarly, Chesler (1972) points out that a "social tolerance" for female displays of 
emotion or helplessness does not mean that such "conditioned behaviors" are valued or treated kindly: "husbands and clinicians experience and judge such female behavior as annoying, inconvenient, stubborn, childish, and tyrannical." Fishman (1983) says, "When they attempt to control conversations temporarily, women often 'start' arguments." While the ways that men and women are socialized to use language contain inherent inequalities, some writers also mention that language about women may be discriminatory. Language may be sexist by being "androcentric"- "the man in the street" and by being "blatantly offensive"- "the blonde in fatal accident" (Cameron 1985). Besides discrimination in discourse about women, sexism is also seen in words which denigrate women's actual speech (Warner 1989):

$\begin{array}{lllll}\text { chatter } & \text { tattle scold } & \text { screech } & \text { nag } \\ \text { gossip } & \text { complain } & \text { wheedle } & \text { rail } & \text { gush }\end{array}$

The connotations of these words support Lakoff (1975) and Chesler (1972) in their contention that females are socialized to use gender-specific language, and then are censured for doing so.

Discrimination in linguistic research. The political perspective on gender-variation in language can be used to look for biases in research. Cameron (1985) points out that findings of gender differences may be research artifacts; she says that studies of male interaction tend to use hierarchical groups, while studies of female interaction use only small intimate groups, so that the samples per se may 
account for the finding of male-competition vs. femalecooperation traits. Research may be flawed by sexist methodology, such as assuming a woman's SES to be derived from her husband's occupation, or by sociolinguistic interviewers being male (Cameron 1985).

Linguistic research often confirms stereotypes by assuming a "norm and deviation framework" in which white middle-class male language is the norm (Cameron 1985). In 1915, Sapir published a study on "abnormal speech types" among the Nootka, presuming certain males to be the norm; the deviants included dwarfs, fat men, hunchbacks, cowards, left-handed men, and women (Key 1975). More recently, most ethnographers used male language forms as "basic," and described women's language as the "derived" (Bodine 1975).

Cameron (1985) says that feminist language research is difficult because (1) feminist concerns, such as "talking a lot" or "competition" are hard to isolate as quantifiable variables, and (2) the measurable variables used by sociolinguists are hard to connect to relevant meanings. It may also be easy to accept untested stereotypes about women's language ("folklinguistic" beliefs), changing only the sexist negative evaluation to a positive feminist one (Cameron 1985). Poorly defined variables and untested conclusions are cited as criticisms of Lakoff's work, especially considering that empirical research has not supported some of her hypotheses (Cameron 1985). 
The domination perspective is used to explain gender differences in language in the sense that "micro-political structures" (Thorne and Henley 1975) represent macro-level institutions of social control and power. According to this viewpoint, language variation is not a benign display of gender, nor an egalitarian cultural difference; it benefits males, devalues females, and perpetuates the hierarchy of gender. Conflict is not seen as a result of semantic misunderstanding, but as an inevitable result of male domination of females who "start" arguments, if the females are perceived as resisting their subordinate, muted, status.

\section{CHAPTER SUMMARY}

Language varies according to the gender of the speaker, the person being spoken to, the person being spoken about, and the person(s) being spoken for. While some cultures include sex-differential language forms, speakers of Western languages use sex-preferential forms, which vary between males and females only in degree of usage.

Explanations for gender variation in language include the dramaturgical, the cross-cultural and the political; these may be used to analyze micro-level interaction variables as they relate to macro-level social institutions. 


\section{CHAPTER III}

\section{METHODOLOGY}

Compared to investigations of gender differences in the production of speech, little research has been done to look at systematic variation in the interpretation of speech (Holtgraves 1991). Few studies have compared differences found in cross-sex interactions with those found in same-sex conversation (Carli 1990). Laboratory experiments have tended to assign dyads to task-oriented interactions only, the type of communication in which men may be most assertive, and this exclusion of affiliation-related interactions may influence the findings of male domination in conversations (Smith 1985). Crosby, Jose and WongMcCarthy suggest that research focus on conflict-related variables:

...researchers might make divisions into good and bad interchanges, whether the interchanges are labeled as such by the participants themselves or by the researchers. Once such divisions have been made, one could assess and catalogue the factors that distinguish between good and bad exchanges (1981, p. 165).

It has been suggested that conversation should be analyzed by using two-part exchanges: "The power of the single interchange is abundantly clear, since so much hinges on it as a social event despite its brevity" (Speier 1973). 
An experiment was designed to incorporate these recommendations in an investigation of the problem of gender differences in interpretations of affiliative conversations.

\section{RESEARCH DESIGN}

Based on a review of the literature, a basic assumption was made that men and women will interpret conversations differently, and two specific hypotheses were posed for this research:

H1- That male and female subjects'
interpretations of male speakers will be
more similar than will male and female
subjects' interpretations of female
speakers. This expectation is derived
from Fishman's (1983) indication that
women do more conversational "work."
H2- That women and men will vary in rating
conversations as likely to result in
conflict; men's ratings of conflict
will relate to their interpretations of
speakers as being "controlling," and
and women's ratings of potential
conflict will relate to their
interpretation of speakers as being
"rejecting." The hypothesis is from
Tannen's (1990) suggestion that
conversation is linked to "independence"
by men and to "intimacy" by women.

A 2 (gender of initiating speaker) by 2 (gender of responding speaker) by 2 (gender of subject) factorial design was used. Dependent variables were embedded in ten interpretations for the hypothetical speakers and in a rating of potential conflict.

Separate sets of five interpretations were used for the initiating speaker (speaker A) and five interpretations for 
the responding speaker (speaker $B$ ). For speaker $A$, the interpretations were: (1) "perceived criticism" and "perceived illicit demand" (unreasonable expectation), two variables found to precipitate conflict in interactions (Peterson 1983); (3) "perceived request for a decision" and (4) "perceived attempt at consensus-building," two variables suggested as gender-related features of conversation by Tannen (1990); and (5) "perceived direct interpretation" (words are taken at face-value), a filler included because Holtgraves (1991) found that it did not vary by gender of subject nor gender of speaker.

For speaker $B$, the responding speaker, interpretations were: (1) "perceived criticism" and (2) "perceived rebuff (rejection)," both from Peterson (1983); (3) "perceived decision being made" and (4) "perceived attempt at consensus-building," from Tannen (1990); and (5) the filler "perceived direct interpretation" from Holtgraves (1991).

The dependent variable for rating the likelihood of conflict was suggested by Crosby, Jose and Wong-McCarthy (1981), who encouraged research on "good and bad interchanges," and by Lowery, snyder and Denney's (1976) study of perceived aggression and counteraggression.

\section{STIMULUS MATERIALS}

For this research, four hypothetical scenarios depicting dyads having everyday-type conversations were 
written, following Holtgraves (1991) and Garcia, Milano and Quijano (1989). (see Figure 3 for text.)

Hypothetical speakers' relationships were ambiguous, to allow them to appear to include cross-sex and same-sex intimate dyads such as friends, siblings or spouses. The conversations were initiated by speaker A making a statement or asking a question, followed by speaker B's brief response, one follow-up remark by $A$, and another short response by $B$. Dyads in scenarios were shown as being alone and not discussing other people, to emphasize the independent variables of "speaker" and "spoken-to," and to avoid the extraneous variables of the "spoken-about" or the "spoken-for-audience" as described by Key (1975) .

Each scenario was systematically modified to vary by sex of speaker $A$ and speaker $B$, resulting in four versions of each vignette: female/female, male/male, female/male, and male/female, following Derlega and Chaikin (1976). Gender of speakers was manipulated by use of gender-specific names, chosen for their similarity; i.e., a speaker who is "Tim" becomes "Tina" in other versions of the same scenario. (See Appendix A for an example of one version of a stimulus booklet. See Appendix B for a chart of gender-specific names used in the four versions of each scenario.)

Booklets containing all four scenarios were prepared, with the order of presentation of the stories held constant. Genders of hypothetical speakers within the vignettes were 


\section{Story 1.}

$A$ and $B$ are helping a friend move to a new apartment. While their friend goes out to get pizza, $A$ and $B$ are packing books into boxes.

A: "There are still a lot of books left to pack."

B: "I know."

A: "We don't have enough boxes, do we?"

B: "Yes, we do."

\section{Story 2 .}

$A$ and $B$ are on their way back from a trip to the beach. The car doesn't have a tape player, and they're too far up in the mountains to listen to the radio.

A: "Looks like the country's in a bad recession."

B: "Yeah."

A: "If the economy keeps going downhill, my job's going to B: $" \mathrm{Hm} . "$ be on the line. I hope I don't get laid off."

\section{story 3 .}

$A$ and $B$ meet at a restaurant for lunch. After placing their food orders, A gets out a page torn from a magazine. It is an advertisement for a jacket.

$\underline{A}$ : "I'm thinking of getting this jacket. What do you think?"

B: "It's okay."

$\underline{A}$ : "I can't decide if it looks right for me."

B: "Get it if you like it."

\section{Story 4 .}

$A$ and $B$ are on their way to see a movie.

A: "I hope we've got enough money."

B: "The tickets are only three dollars each."

A: "No, that's not what I meant. I mean, I hope we've got enough money to get popcorn and something to drink, too."

B: "I'm not worried about it."

Figure 3. Text of scenarios in stimulus material. 
systematically manipulated, so that the four possible combinations of the hypothetical speakers' genders were presented in every possible sequence. ${ }^{7}$ Every booklet presented one of each gender-pair of speakers, with the content of the four stories intended to vary sufficiently to distract subjects from focusing on speakers' genders as the variable of interest.

Each scenario was followed by possible interpretations for speaker A, the initiator, and for speaker B, who responds. To create the interpretations, the dependent variables were expressed in everyday language, following Marwell and Schmitt (n.d.). Interpretations were rotated in order of presentation across the four scenarios. The final dependent variable was a rating of the likelihood of conflict for each conversation. (See Appendix A.)

\section{PROCEDURE}

Experimental stimulus booklets were printed on legalsize paper to ensure legibility. They were administered randomly. Subjects were instructed to express their own "opinions" on the "questionnaire," as if the booklets were identical survey instruments. A pair of 0-5 scales was printed on the introductory page of the booklet; before

${ }^{7}$ Four versions of four scenarios systematically arranged in all permutations equals 24 sets of scenarios, based on the principles of a balanced Graeco-Latin square. For 216 subjects, 9 sets of scenarios would be presented. 
beginning to work on the booklets, subjects completed the sample scales and the instructions for their use were reviewed. Subjects completed the booklets during classes, requiring about 15 minutes.

Subjects rated each of the forty interpretations for speakers, and each of the four measurements of potential conflict for conversations, according to their judgement of its likelihood in relation to the scenario presented. For all ratings, six-point Likert-type scales were used, ranging from $0=$ "not at all likely," to $5=$ "very likely," following Holtgraves (1991) and Garcia, Milano and Quijano (1989).

Demographic questions assessed subject gender, age, academic major, and whether English was the subject's native language. This research depended on connotative judgements which may vary because of childhood language socialization, so stimulus booklets completed by non-native English speakers were not used for data analysis. A total of 216 subjects remained after those deletions.

Volunteer subjects were 138 female and 78 male undergraduates at portland State University, an urban commuter campus with a diverse student population. The age range was 18-53, with a mean age of 25 for both males and females. Subjects were recruited from day and evening sections of an upper-division marriage course, from introductory sociology, and from a statistics course; virtually all students present in each class participated. 
The subjects represented over 40 academic majors, with less than $20 \%$ of the sample from any one major.

Data analysis was conducted interactively, using sPSs on a personal computer. Analyses of variance (ANOVAs) were performed on a random subsample of 144 cases ( 72 male, 72 female) balanced with 18 cases per cell. Cases were treated as blocks when drawing the subsample from the total sample. The total sample was not used for ANOVAs because there were unequal numbers of males and females in the sample, and because random assignment of stimulus material resulted in unequal numbers of subjects in cells. For all other analyses, the total sample of 216 cases was used. 


\section{RESULTS}

The first finding was that subjects' mean responses for each dependent variable across scenarios varied more than anticipated. The design for data analysis was modified by omitting the planned pooling of responses for each dependent variable across the four scenarios. Table I compares sample means for all dependent variables across the four scenarios. Correlations of dependent variables across scenarios showed no predictable pattern of responses, so data analysis was conducted separately for each scenario.

The variation found in the means for responses between the four stories may have resulted from characteristics of the scenarios and/or of the subjects. In two vignettes, the speakers ask questions, a form of conversation which may have elicited interpretations which varied from the other two conversations in which all remarks were made as statements. The content of the vignettes, such as money or clothing, may have influenced subjects' ratings of the speakers' conversations. These combinations of form and content may have been the cues used by subjects to make varying judgements between the stories. As subjects were unaware that speakers' genders were the variable of interest 


\section{TABLE I \\ MEAN OVERALL RATINGS \\ ALL VARIABLES}

\section{DEPENDENT VARIABLE}

1

FOR SPEAKER A

CRITICISM BY A

$$
\begin{gathered}
.85 \\
(1.07) \\
1.60
\end{gathered}
$$

DEMAND BY A

(1.33)

A REQ. DECISION 2.28

$$
(1.56)
$$

1.44

(1.49)

DIR. INTERP. / A

3.33

(1.46)

\section{SCENARIO NUMBER}

2

3

\begin{tabular}{|c|c|c|c|c|}
\hline CRITICISM BY B & $\begin{array}{c}1.08 \\
(1.13)\end{array}$ & $\begin{array}{r}.47 \\
(.86)\end{array}$ & $\begin{array}{c}1.13 \\
(1.16)\end{array}$ & $\begin{array}{c}2.17 \\
(1.46)\end{array}$ \\
\hline REBUFF BY B & $\begin{array}{c}1.58 \\
(1.48)\end{array}$ & $\begin{array}{r}3.15 \\
(1.55)\end{array}$ & $\begin{array}{c}2.51 \\
(1.44)\end{array}$ & $\begin{array}{r}2.40 \\
(1.33)\end{array}$ \\
\hline DECISION BY B & $\begin{array}{c}2.81 \\
(1.47)\end{array}$ & $\begin{array}{c}.99 \\
(1.16)\end{array}$ & $\begin{array}{c}1.21 \\
(1.20)\end{array}$ & $\begin{array}{c}4.12 \\
(1.16)\end{array}$ \\
\hline CONSENSUS / B & $\begin{array}{r}.56 \\
(.83)\end{array}$ & $\begin{array}{r}.75 \\
(.91)\end{array}$ & $\begin{array}{l}.54 \\
(.70)\end{array}$ & $\begin{array}{r}.49 \\
(.76)\end{array}$ \\
\hline DIR. INTERP./B & $\begin{array}{c}3.31 \\
(1.39)\end{array}$ & $\begin{array}{c}2.55 \\
(1.19)\end{array}$ & $\begin{array}{c}4.17 \\
(\quad .99)\end{array}$ & $\begin{array}{c}3.74 \\
(1.60)\end{array}$ \\
\hline
\end{tabular}

4

$\begin{array}{lcccc}\text { CONSENSUS/A } & (1.56) & (1.10) & (1.39) & (1.55) \\ & 1.44 & 3.23 & 4.11 & 2.17 \\ \text { DIR. INTERP./A } & (1.49) & (1.23) & (.92) & (1.55) \\ & 3.33 & 2.27 & 3.82 & 4.34 \\ & (1.46) & (1.47) & (.98) & (.89)\end{array}$

FOR SPEAKER B

\section{FOR CONVERSATION}

CONFLICT

$$
\begin{array}{cccc}
1.95 & 1.52 & 1.90 & 2.24 \\
(1.25) & (1.34) & (1.37) & (1.41)
\end{array}
$$

$\mathrm{N}=216$

Standard deviations shown in parentheses. 
in this study, they may have attended to the differences in the stories' settings and activities. ${ }^{8}$

A similar effect was found by Derlega and Chaikin (1976) when written scenarios were the stimulus materials for an experiment in which ratings of hypothetical speakers' conversations were the dependent variables: subjects' overall ratings varied by scenario content. Carli (1990) did not find this effect after randomly assigning discussion topics to dyads participating in a laboratory experiment. It may be that written scenarios are conducive to more variation because the subject has little to work with, as compared to more complex stimuli such as videotaped interactions or participation in actual conversations.

For the second finding, means tables were constructed to determine whether there was systematic gender variation in overall responses. On 0-5 scales, the mean rating for all dependent variables by all female subjects was 2.16 . The mean rating for all dependent variables by all male subjects was 2.17. Table II includes the overall mean ratings made by subjects. The similarities in mean ratings by males and females indicated that there were not systematic gender differences between subjects in ratings of hypothetical speakers. The mean responses also indicated no systematic

${ }^{8}$ When debriefing a group of subjects, it was clear that they had tried to determine what the research was about. They asked if it was related to the item measuring potential conflict, because they noticed that question in the same location at the bottom of each page following every scenario. 
SPEAKER

GENDER

\section{SEX OF SUBJECTS}

$\frac{\text { MALE }}{n=78} \quad \frac{\text { FEMALE }}{n=138}$

FEMALE SPEAKER A

$$
2.40
$$$$
\text { (1.27) }
$$$$
\text { 2. } 32
$$$$
\text { (1.23) }
$$

MALE SPEAKER A

$$
\begin{array}{cc}
2.26 & 2.38 \\
(1.19) & (1.26)
\end{array}
$$

FEMALE SPEAKER B

$$
\begin{array}{cc}
1.96 & 1.98 \\
(1.24) & (1.16)
\end{array}
$$

MALE SPEAKER B

$$
2.04 \quad 1.96
$$$$
(1.22) \quad(1.13)
$$

LIKELIHOOD OF CONFLICT

$$
\begin{array}{cc}
1.98 & 1.92 \\
(1.32) & (1.36) \\
2.17 & 2.16 \\
(1.23) & (1.20)
\end{array}
$$

Standard deviations shown in parentheses.

variation in the use of the 0-5 rating scales, nor in relation to subject age or academic major.

\section{HYPOTHESIS 1}

To test the first hypothesis, that male and female subjects' ratings for interpretations of male speakers would be more similar than ratings of female speakers, a three-way 
analysis of variance (ANOVA) was performed with the independent variables of subject gender, speaker A gender (initiator), and speaker B gender (responding speaker). The ten dependent variables for interpretations in four scenarios required forty separate analyses. Four two-way interactions supporting the hypothesis were found.

Table III presents findings for scenario 1. Female subjects interpreted the dependent variable of a "perceived illicit demand by speaker A" about equally for a speaker A of either gender, rating it as only slightly more likely than male subjects rated it for a male speaker A. But male subjects rated an "illicit demand" as significantly more likely if a female initiated the conversation. Means tables showed this effect in scenario 4 , short of significance.

\section{TABLE III}

TWO-WAY INTERACTION IN SCENARIO 1

ILLICIT DEMAND BY SPEAKER A

BY SUBJECT SEX

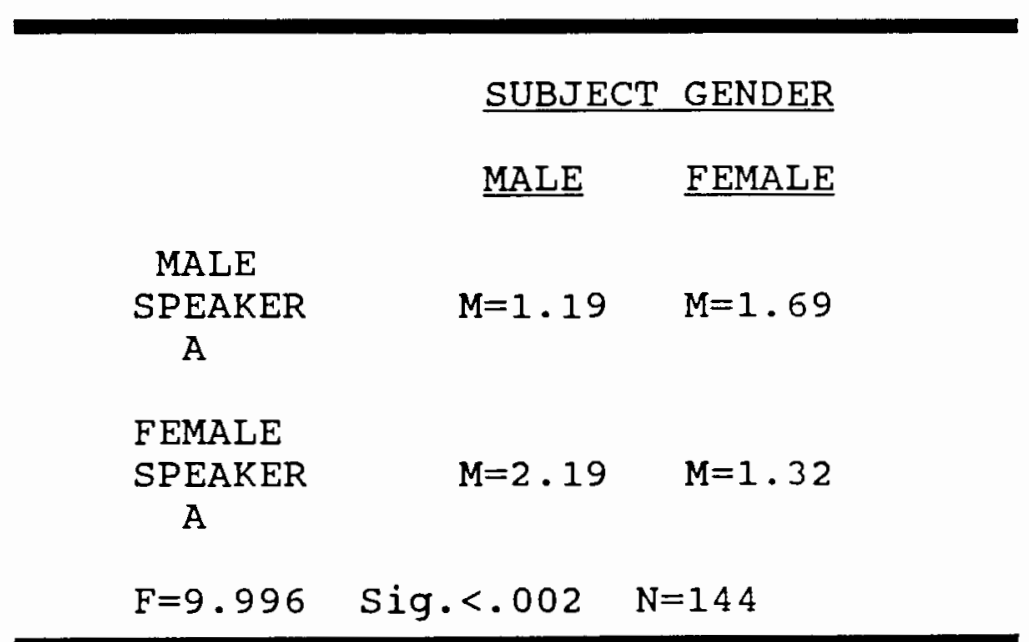


Table IV presents a similar finding. For the variable measuring "consensus-building by speaker $A$," in scenario 2 , female subjects' ratings were similar for both male and female speakers, and males rated it as about equally likely for a male speaker $A$. Male subjects rated it significantly more likely for a female initiating speaker. Means tables did not show this effect for interpreting speaker $A$ as attempting to build consensus in the other scenarios.

\section{TABLE IV}

TWO-WAY INTERACTION IN SCENARIO 2 CONSENSUS BY SPEAKER A BY SUBJECT SEX

\begin{tabular}{|c|c|c|}
\hline & \multicolumn{2}{|c|}{ SUBJECT GENDER } \\
\hline & MALE & FEMALE \\
\hline $\begin{array}{l}\text { MALE } \\
\text { SPEAKER } \\
\text { A }\end{array}$ & $M=3.03$ & $\mathrm{M}=3.19$ \\
\hline $\begin{array}{l}\text { FEMALE } \\
\text { SPEAKER } \\
\text { A }\end{array}$ & $M=3.67$ & $M=3.03$ \\
\hline$F=3.937$ & Sig.<.049 & $N=144$ \\
\hline
\end{tabular}

Table $\mathrm{V}$ shows a similar two-way interaction. For a "perceived rebuff by speaker B" in scenario 1 , females interpreted a male or female speaker $B$ about the same way that males interpreted a male, but males interpreted a "rebuff" as significantly more likely for a female speaker B. This effect was not seen in the other vignettes. 


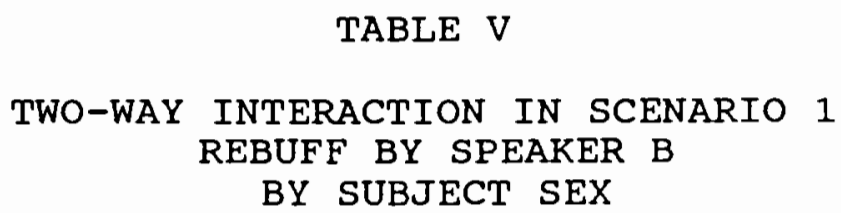

\begin{tabular}{|c|c|c|}
\hline & SUBJECT & GENDER \\
\hline & MALE & FEMALE \\
\hline $\begin{array}{c}\text { MALE } \\
\text { SPEAKER } \\
\text { B }\end{array}$ & $M=1.25$ & $M=1.49$ \\
\hline $\begin{array}{l}\text { FEMALE } \\
\text { SPEAKER } \\
\text { B }\end{array}$ & $M=2.14$ & $M=1.43$ \\
\hline$F=3.83$ & Sig.<.05 & 144 \\
\hline
\end{tabular}

In Table VI, results are presented for the dependent variable of a "direct interetation for speaker B" in scenario 1 . It was rated by female subjects as equally descriptive of male and female speakers. Male subjects rated females as significantly less likely to be "directly interpreted." Means tables showed this effect for this variable in scenario 4 , short of significance.

\section{Summary for Hypothesis 1}

of forty interpretations of dependent variables made by each subject, males' interpretations of female speakers varied significantly from females' interpretations on four variables, and also from all subjects' interpretations of male speakers. These findings are in the direction 
TWO-WAY INTERACTION IN SCENARIO 1

DIRECT INTERPRETATION FOR SPEAKER B

BY SUBJECT SEX

\begin{tabular}{|c|c|c|}
\hline & \multicolumn{2}{|c|}{ SUBJECT GENDER } \\
\hline & \multicolumn{2}{|c|}{ FEMALE } \\
\hline $\begin{array}{l}\text { MALE } \\
\text { SPEAKER } \\
\text { B }\end{array}$ & $M=3.75$ & $M=3.19$ \\
\hline $\begin{array}{l}\text { FEMALE } \\
\text { SPEAKER } \\
\text { B }\end{array}$ & $M=2.81$ & $M=3.51$ \\
\hline$F=7.82$ & Sig.<.00 & $=144$ \\
\hline
\end{tabular}

hypothesized. They were the only two-way interactions between sex of subject and sex of the interpreted speaker. There were no interactions in the opposite direction.

\section{HYPOTHESIS 2}

The second hypothesis was tested first by performing three-way ANOVAs for each scenario with the independent variables of subject gender, speaker A gender, speaker B gender, and the dependent variable of subjects' ratings of the likelihood of conflict.

Stepwise multiple regression analyses were then conducted for each scenario, with the rating of potential conflict as the dependent variable. Variables which were analyzed as dependent in other phases of analyses were used 
as predictor variables for the multiple regression, to identify variables related to subjects' ratings of potential conflict. Male subjects were hypothesized to rate conflict as more likely when they rated the conversation as relating to the issue of being controlled. Female subjects were expected to rate conflict as more likely when they also judged the conversation as relating to the issue of being rejected.

\section{Analysis of Variance}

Tables VII and VIII show main effects found with ANOVAs for the dependent variable of "potential conflict" in scenarios 2 and 4 by the independent variable of gender of speaker A (initiating speaker). Conflict was rated to be significantly more likely with a female speaker A.

This same effect, short of significance, was seen in the means tables for the total sample for the other two scenarios ( 1 and 3 ). Subjects tended to rate conflict as more likely if a female initiated the conversation. A relationship between "likelihood of conflict" and female gender of the initiating speaker was found in every vignette, and was significant in scenarios 2 and 4 .

Tables IX and $X$ present significant two-way interactions between genders of speaker A and speaker B for ratings of potential conflict in scenario 2 and scenario 3 . In ratings for scenario 2 (Table IX), conflict was rated as most likely for a conversation between a female initiator 
TABLE VII

MAIN EFFECT IN SCENARIO 2 FOR POTENTIAL CONFLICT AND SEX OF INITIATING SPEAKER

\begin{tabular}{|c|c|}
\hline \multicolumn{2}{|c|}{ SPEAKER A GENDER } \\
\hline MALE & FEMALE \\
\hline$M=1.29$ & $M=1.75$ \\
\hline$F=4.724$ & sig.<.031 \\
\hline
\end{tabular}

TABLE VIII

MAIN EFFECT IN SCENARIO 4 FOR POTENTIAL CONFLICT AND SEX OF INITIATING SPEAKER

\begin{tabular}{cr}
\multicolumn{2}{c}{ SPEAKER A GENDER } \\
MALE & FEMALE \\
$\mathrm{M}=2.00$ & $\mathrm{M}=2.48$ \\
$\mathrm{~F}=4.177$ & $\mathrm{sig} \cdot<.043 \quad \mathrm{~N}=144$
\end{tabular}

and a male responding speaker. All other gender combinations of interacting pairs in that scenario were rated about equally. For scenario 3 (Table $\mathrm{X}$ ), the pattern of conflict rating was significant for both types of crosssex dyads. Conflict was rated as most likely if the conversation was initiated by a male speaking to a female. Conflict was also rated to be likely if conversation was 
TABLE IX

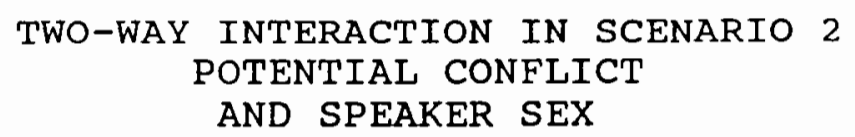

\begin{tabular}{|c|c|c|}
\hline & \multicolumn{2}{|c|}{ SPEAKER A GENDER } \\
\hline & MALE & FEMALE \\
\hline $\begin{array}{l}\text { MALE } \\
\text { SPEAKER } \\
\text { B }\end{array}$ & $\mathrm{M}=1.14$ & $M=2.14$ \\
\hline $\begin{array}{l}\text { FEMALE } \\
\text { SPEAKER } \\
\quad \text { B }\end{array}$ & $M=1.44$ & $M=1.36$ \\
\hline$F=6.598$ & sig.<.011 & $N=144$ \\
\hline
\end{tabular}

\begin{tabular}{|c|c|c|c|}
\hline \multicolumn{3}{|c|}{$\begin{array}{c}\text { TWO-WAY INTERACTION IN SCENARIO } \\
\text { POTENTIAL CONFLICT } \\
\text { AND SPEAKER SEX }\end{array}$} & 3 \\
\hline & $\begin{array}{l}\text { SPEAK } \\
\text { MALE }\end{array}$ & $\begin{array}{l}\text { ER A GENDER } \\
\text { FEMALE }\end{array}$ & \\
\hline $\begin{array}{l}\text { MALE } \\
\text { SPEAKER } \\
\quad \text { B }\end{array}$ & $M=1.50$ & $M=2.06$ & \\
\hline $\begin{array}{l}\text { FEMALE } \\
\text { SPEAKER } \\
\quad \text { B }\end{array}$ & $M=2.42$ & $M=1.64$ & \\
\hline$F=8.963$ & $\operatorname{sig} .=.003$ & $N=144$ & \\
\hline
\end{tabular}


initiated by a female with a male. Same-sex dyads were rated as less likely to experience conflict following their conversation.

Table XI depicts a significant three-way interaction obtained between all independent variables and the dependent variable of conflict rated by subjects. The ANOVA showed all subjects rating conflict as most likely for conversations initiated by a female with a male. For other combinations of speakers, there were between-subjects differences. A conversation initiated by a male with a female was rated as more likely to result in conflict by

\section{TABLE XI}

THREE-WAY INTERACTION IN SCENARIO 2 POTENTIAL CONFLICT BY SPEAKER SEX AND BY SUBJECT SEX

SUBJECT GENDER

MALE

FEMALE

SPEAKER A GENDER

MALE

MALE

SPEAKER

$B$

FEMALE

SPEAKER

B

$\mathrm{F}=7.292 \quad \mathrm{Sig} .<.008 \quad \mathrm{~N}=144$

$\mathrm{F}=7.292 \mathrm{Sig} \cdot<.008 \quad \mathrm{~N}=144$
SPEAKER A GENDER

MALE FEMALE

$M=0.72 \quad M=2.17$

$M=2.11$

$M=1.50$

$M=2.00$

$\mathrm{M}=1.22$ 
female subjects than by male subjects. When a male initiated the conversation with another male, conflict was seen as more likely by male subjects than by female subjects. Potential conflict for conversation initiated by a female with another female was rated about equally by all subjects.

Summary for ANOVA. The ANOVA resulted in two main effects and two significant two-way interactions between subjects' ratings for potential conflict and the gender of speakers. Significant variation between ratings by male and female subjects was seen in a three-way interaction between gender of subjects and both speakers in scenario 2. For that vignette, male and female subjects tended to rate female-initiated conversations as having equally high potential for conflict, but varied in interpretations of male-initiated conversations by rating conflict as more likely if the speaker $B$ was the same gender as the subject.

\section{Means tables}

The means tables for the total sample's $(n=216)$

responses on the variable of conflict potential revealed effects of speaker gender. For each of the four scenarios, the highest mean ratings for potential conflict were seen when the conversation occurred between a cross-sex dyad. For male subjects $(n=78)$, the highest ratings for likelihood of conflict was for conversations initiated by a male with a female in two scenarios, $1(M=2.45)$ and 3 
$(M=2.25)$, and for conversations initiated by a female with a male in scenarios $2(M=2.15)$ and $4(M=2.85)$. For female subjects $(n=138)$, the highest ratings for likelihood of conflict was for conversations initiated by a female with a male, across all four scenarios. (Scenario 1, $M=1.94$; scenario $2, \mathrm{M}=2.11$; scenario $3, \mathrm{M}=2.35$; scenario $4, \mathrm{M}=2.88$.)

Multiple regression analysis

To test the hypothesis that male and female subjects would have different reasons for rating that conflict would follow a conversation, stepwise multiple regression analyses were conducted with the dependent variable of potential conflict. The two independent variables, sex of speaker A and of speaker B, were used as predictor variables, as well as the ten variables for interpretations of the conversations. Separate regressions were done for male subjects and for female subjects by selecting cases for analysis by the variable of subject gender.

It was hypothesized that males' ratings for conflict would increase in relation to the issue of being controlled, represented by the variable of an "illicit demand." It was expected that females' ratings of conflict would increase in relation to the issue of being rejected, represented by the variable of a "rebuff". Tables XII through XV present the results of the stepwise regression analyses.

The relationships between subjects' ratings of the likelihood of conflict and the predictor variables do not 
support the research hypothesis as it was formulated. However, a pattern of relationships can be seen which suggests that there may be gender-related variation in subjects' judgements.

For scenario 1, males' ratings of potential conflict were related to their perception of a rebuff by speaker $B$, the responding speaker. But for females, about an equal amount of variation in their ratings of conflict was related to their interpretation that speaker A, the initiator, was making an excessive demand. Females also seemed to base their ratings of conflict on their perceptions of criticism by both speakers in the vignette.

Scenario 2 appeared to provide male and female subjects with the same reason, an excessive demand by the initiating speaker, to rate conflict as a possible outcome of the conversation. Males perceived criticism by speaker A as also preceding conflict, but female subjects did not base their judgement of potential conflict on criticism by either speaker. Female subjects' ratings for conflict related to perceptions that a direct interpretation of speaker $B$ was unlikely, and to their rating of speaker $A$ as attempting to build consensus, and also to speaker A being female. 9 For scenario 3 (Table XIV), males again indicated that conflict was likely in relation to an excessive demand by

${ }^{9}$ The relationship between predicted conflict and gender of speaker A was significant in the ANOVA. See Table IX. 
TABLE XII

PREDICTORS FOR CONFLICT IN SCENARIO 1

MALE SUBJECTS

$\mathrm{R}^{2}=.15$

REBUFF BY $B$

beta $=.39 \mathrm{~T}=3.69$

$\mathrm{N}=216$

Variables entered $\mathrm{p}<.05$
FEMALE SUBJECTS

$\mathrm{R}^{2}=.28$

DEMAND BY A

bet $a=.41 \quad T=5.29$

CRITICISM BY B

beta $=.29 \mathrm{~T}=3.82$

CRITICISM BY A

beta $=.17 \mathrm{~T}=2.00$

\section{TABLE XIII}

PREDICTORS FOR CONFLICT IN SCENARIO 2

\section{MALE SUBJECTS}

$\mathrm{R}^{2}=.24$

DEMAND BY A

beta $=.41 \quad \mathrm{~T}=3.84$

CRITICISM BY A

bet $\mathrm{a}=.28 \quad \mathrm{~T}=2.77$

$\mathrm{N}=216$

Variables entered $\mathrm{p}<.05$

\section{FEMALE SUBJECTS}

$\mathrm{R}^{2}=.19$

DEMAND BY A

beta $=.31 \quad \mathrm{~T}=3.84$

DIR. INT. OF B

bet $\mathrm{a}=-.20 \mathrm{~T}=-2.49$

GENDER OF A

beta $=.17 \quad \mathrm{~T}=2.17$

CONSENSUS BY A

beta $=.17 \quad \mathrm{~T}=2.02$ 
MALE SUBJECTS

$\mathrm{R}^{2}=.17$

CRITICISM BY B

bet $a=.33 \quad T=3.05$

DEMAND BY A

beta $=.25 \mathrm{~T}=2.32$
FEMALE SUBJECTS

$\mathrm{R}^{2}=.16$

DEMAND BY A

beta $=.26 \quad \mathrm{~T}=3.07$

SUBJECT AGE

bet $\mathrm{a}=-.20 \mathrm{~T}=-2.45$

CONSENSUS BY A

beta $=.17 \mathrm{~T}=2.11$

REBUFF BY B

beta $=.19 \mathrm{~T}=2.10$

$N=216$

Variables entered $\mathrm{p}<.05$

\section{TABLE XV \\ PREDICTORS FOR CONFLICT IN SCENARIO 4}

\section{MALE SUBJECTS}

$R^{2}=.14$

CRITICISM BY B

beta $=.38 \quad \mathrm{~T}=3.56$

$\mathrm{N}=216$

Variables entered $\mathrm{p}<.05$
FEMALE SUBJECTS

$R^{2}=.32$

CRITICISM BY B

beta $=.49 \mathrm{~T}=6.49$

CRITICISM BY A

beta $=.29 \quad \mathrm{~T}=3.96$ 
speaker A. They also rated it as likely in relation to perceived criticism by speaker B. Again, females also perceived speaker $A^{\prime}$ s excessive demand as likely to precede conflict, and as in scenario 2 , they did not perceive either speaker's criticism as being especially relevant. Females again related conflict as more likely if speaker $A^{\prime} s$ was rated as attempting to build consensus. They considered a perceived rebuff by speaker $B$ as leading to conflict. For this one scenario, there was an effect of subject age, with younger age of female subject relating to perception of potential conflict. (A means table showed this to be an effect of women age 18-20 rating conflict as more likely than older women rated it.)

In scenario 4 (Table XV), both male and female subjects seemed to rate conflict as highly likely because of perceived criticism by speaker B. Females also appeared to take criticism by speaker $A$ into account when rating the potential for conflict.

It may be that the original hypothesis was too narrow in defining which dependent variables would be useful for measuring the sense of "being controlled," hypothesized to be mens' reason for rating conflict as likely, as well as too narrow in defining which variables would measure a sense of being "rejected," hypothesized to be womens' reason for rating conflict as likely. If "being controlled" and "losing independence," the concerns which Tannen (1990) 
suggests are paramount for males in conversation, are felt by men when they perceive excessive demands, criticism and rebuffs, then the hypothesis for males was supported by the results of the regression analysis. If "being rejected" and "losing intimacy," the concerns suggested by Tannen as being primary for women, are felt by women when they perceive excessive demands, criticism, rebuffs, consensus-building attempts by speakers who begin conversations, and underlying indirect meanings by responding speakers, then the hypothesis regarding females was supported by the results.

\section{Summary for Hypothes is 2}

Ratings of likelihood of conflict showed effects of subject gender and speaker gender. For all four scenarios, conflict was rated as more likely between cross-sex dyads than between same-sex dyads. Male subjects rated conflict as most likely for interactions initiated by a male in two scenarios, and most likely for a female-initiated interactions in the other two scenarios. Females rated female-initiated conversations as the most likely to result in conflict in all four scenarios. These results were significant in two of the four vignettes.

Interpretations of speakers which related to ratings of potential conflict weré somewhat different for male and female subjects. For men, four variables measuring perceived criticism, rebuffs and excessive demands were the only predictors of their ratings of likelihood of conflict. 
For women, eight variables measuring perceived criticism, excessive demands, consensus-building attempts, rebuffs, direct interpretations, speaker gender, and age of subject were predictors of their ratings of potential conflict.

\section{ADDITIONAL FINDINGS}

Eight unexpected results were found with the ANOVAs.

Tables XVI and XVII present two main effects found for "consensus-building" attempts by speaker A. For scenario 1, female subjects were more likely to interpret the initiating speaker as trying to build consensus. For scenario 3, male initiating speakers were more likely to be interpreted as building consensus.

Main effects were obtained for a perceived "rebuff" by speaker $B$ in two scenarios. A remark was more likely to be interpreted as a "rebuff" if a male was speaking, in scenario 3 and in scenario 4 . Tables XVIII and XIX depict these results.

A significant two-way interaction was obtained in scenario 4 between speaker A and speaker B for a "rebuff." Subjects were most likely to interpret speaker B's remarks as a "rebuff" if both speakers were male, seen in Table XX. A main effect was found for speaker $A$, the initiating speaker, in scenario 4 , with a female speaker more likely to be interpreted as making an "illicit demand" (excessive demand). The relationship is shown in Table XXI. 
Two results were obtained in which subjects' interpretations of a speaker were related to the gender of the conversational partner. In scenario 1, a main effect was found for the relationship between a "direct interpretation" of speaker A's remarks and the sex of Speaker B. The initiating speaker was more likely to be interpreted as speaking "directly" if talking to a female, as shown in Table XXII. Table XXIII presents a two-way interaction obtained in scenario 2 , for the perception of criticism by speaker $B$, between the gender of the initiating speaker and the gender of the subject. Subjects were more likely to rate speaker B as "critical" when that speaker was responding to an initiating speaker of the same sex as the subject.

Summary for Additional Findings

Unexpected findings showed females rating consensusbuilding by an initiating speaker as more likely than males rated it in scenario 1 . In scenario 3, female initiating speakers were more likely than males to be interpreted as attempting to build consensus when they spoke. In scenario 4, female initiating speakers were more likely than males to be interpreted as making an excessive demand. Male speaker $B^{\prime}$ 's remarks were more likely than females' to be seen as rebuffs in scenarios 3 and 4 . In scenarios 1 and 2 , ratings for speakers were related to the sex of the other speaker in the conversation. 


\section{TABLE XVI}

MAIN EFFECT IN SCENARIO 1 CONSENSUS-BUILDING

\begin{tabular}{cr}
\multicolumn{2}{c}{ SUBJECT } \\
MALE & $\underline{\text { FEMALE }}$ \\
M=1.06 & M=1.83 \\
F=10.30 Sig.<.00 & $\mathrm{N}=144$ \\
\hline
\end{tabular}

TABLE XVII

MAIN EFFECT IN SCENARIO 3 CONSENSUS-BUILDING

\section{SPEAKER A GENDER}

MALE

$M=4.32$

$F=7.55$
FEMALE

$M=3.90$

$$
\text { Sig.<.00 N=144 }
$$


TABLE XVIII

MAIN EFFECT IN SCENARIO 3

REBUFF BY SPEAKER B

\begin{tabular}{|c|c|c|}
\hline \multicolumn{3}{|c|}{ SPEAKER B GENDER } \\
\hline & MALE & FEMALE \\
\hline & $M=2.76$ & $M=2.25$ \\
\hline $\mathrm{F}=4.69$ & Sig. $<.03$ & $N=144$ \\
\hline
\end{tabular}

TABLE XIX

MAIN EFFECT IN SCENARIO 4

REBUFF BY SPEAKER B

SPEAKER B GENDER

\begin{tabular}{|c|c|c|}
\hline MALE & & FEMALE \\
\hline$y=2.66$ & & $M=2.15$ \\
\hline 5.50 & Sig.<. 02 & $N=144$ \\
\hline
\end{tabular}

$$
F=5.50 \quad \mathrm{Sig} .<.02 \quad \mathrm{~N}=144
$$


TABLE $X X$

MAIN EFFECT IN SCENARIO 4

DEMAND BY SPEAKER A

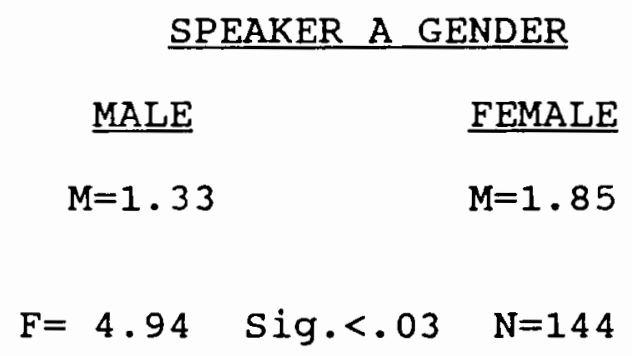

\begin{abstract}
TABLE XXI
TWO-WAY INTERACTION IN SCENARIO 4

REBUFF BY SPEAKER B
\end{abstract}

SPEAKER B GENDER

MALE FEMALE

MALE

SPEAKER

$M=2.97 \quad M=1.97$

A

FEMALE

SPEAKER

$M=2.34 \quad M=2.33$

A

$\mathrm{F}=5.27 \quad \mathrm{Sig} \cdot<.02 \quad \mathrm{~N}=144$ 
TABLE XXII

MAIN EFFECT IN SCENARIO 1

DIRECT INTERPRETATION

\begin{tabular}{|c|c|c|}
\hline \multicolumn{3}{|c|}{ SPEAKER B GENDER } \\
\hline MALE & & FEMALE \\
\hline$M=3.05$ & & $M=3.61$ \\
\hline$F=5.28$ & Sig.<. 02 & $N=144$ \\
\hline
\end{tabular}

TABLE XXIII

TWO-WAY INTERACTION IN SCENARIO 2

CRITICISM BY SPEAKER A

\section{SUBJECT GENDER}

MALE FEMALE

MALE

SPEAKER

$M=.67 \quad M=.28$

$A$

FEMALE

SPEAKER

$M=.33 \quad M=.61$

A

$F=5.43 \quad$ sig.<.02 N=144 


\section{CHAPTER V}

\section{DISCUSSION AND CONCLUSIONS}

The results of this research support the hypotheses and contribute knowledge useful for further investigations.

The testing for the first hypothesis showed four significant findings out of forty analyses. Although the number was not large, those four were in the direction hypothesized. They illustrate the contention underlying the hypothesis: that women do more "work" in conversations, as found by Fishman (1983). Interactional work may require certain groups to interpret others more accurately. It may be in the interest of the less powerful groups to understand those who have more power; the more powerful groups may have less incentive to try to interpret those who are less powerful. If the four results (Tables III-VI) are looked at from the "domination" perspective, they can be seen as evidence of the kind of language differences mentioned by Simkins-Bullock and Wildman (1991): variation which appears to be gender-related actually may be power-related because of women's subordinate social status.

If the results are looked at from the "cross-cultural" viewpoint suggested by Tannen (1990), it isn't as clear how the variation would be explained. If male and female 
subjects had simply evaluated everything differently, or if male and female hypothetical speakers had consistently been rated in different ways, there would seem to be more support for a "different domains" explanation. But as there were a few situations in which women interpreted male speakers' remarks in much the same ways that men did, and men did not interpret female speakers as women interpreted them, the possibility of one-sided understanding exists.

Three of the four significant results were found for scenario 1 , and one result for scenario 2 . It may be that the content or the order of presentation of the scenarios had effects on the findings. If learning or fatigue were effects, then it seems possible that the results of the first scenario are a more reliable indicator of attitudes. But if the task-oriented nature of the dyad's conversation in scenario 1 had an effect, then the results may apply only to that kind of setting. Further research could explore these questions, by rotating the content of hypothetical vignettes and by presenting more scenarios which are clearly task- vs. affiliation-oriented.

The findings in this study which were least expected were for the variables measuring subjects' ratings of potential conflict between the two hypothetical speakers. It was not expected that subjects would so clearly rate conflict as more likely between cross-sex dyads; it is especially interesting considering the design of the study 
and the general variation in responses between the stories. Every subject had the opportunity to rate each of the four gender-combinations of dyads, and everyone was presented with all four scenarios. The scenarios per se generated responses too varied to allow the pooling of data across them, but there were tendencies which became apparent regardless of the content of the stories. If the content of the vignettes had been more provocative, effects of gender variation might have been overshadowed. But as it was, subjects were apparently influenced by the combinations of "what was being done" and "who was doing it."

The most surprising results for potential conflict were obtained as main effects, two-way interactions, and a threeway interaction in ANOVAs. (See Tables VII-XI.) Why was there such an obvious effect of gender in subjects' ratings?

In scenario 2 , when subjects were asked to rate the likelihood of a "fight or argument," they found it most likely if a female had initiated the conversation. Male and female subjects rated such conflict more likely if a female speaker initiated the conversation with a male. One reason the finding was not expected was that the scenario had been written expressly to make it clear that speaker B was not being interruped at a task, and wasn't even trying to listen to the radio. There seemed to be little context to indicate the chance of a fight, but the regression analysis pointed to "an excessive demand by speaker A" as the variable most 
strongly related to ratings of likely conflict. As female subjects seemed to note that speaker A was trying to build consensus, and male subjects did not appear to see that interpretation (and even saw criticism by speaker A) there would be grounds for an argument in "real life.". Seen from the "domination" perspective, the conflict was rated as likely by subjects because a female was too assertive in initiating the conversation with a male. But seen from the "domain" viewpoint as described by Tannen (1990), conflict was rated as likely because the female initiated a discussion of problem topics, the economy and her job, that the male could do nothing about- and therefore had no need to discuss. It may be that the subjects themselves would not be able to explain just why the situation was likely to be troublesome; a study using open-ended questions could be used to look for subjects' own explanations.

In analyzing scenario 4, a main effect of gender of the initiating speaker was obtained. If a female initiated that conversation, about having enough money for refreshments at a movie, an argument was rated as more likely than if a male initiated it. The regression analysis indicated that subjects' interpretations of speaker B being critical of speaker A were related to their ratings of potential conflict. Again, it could be argued that females were seen as too assertive in starting the conversation, and subjects saw a fight brewing because of that. But it can also be 
argued that subjects perceived speaker A as simply trying to get some information, and saw speaker $B$ as reacting in an unnecessarily rude manner; it may be that a kind of chivalry or sense of a norm-violation prompted subjects to rate a fight as more likely when speaker $B$ was perceived as overtly critical of a female.

Scenario 4 included the only instance of a speaker openly correcting a misunderstanding, and the scenario was placed last in the booklets because of it. In the absence of other clues, that small indicator of contention may have contributed to the generally high ratings of likelihood of conflict for the scenario. But the variance between a male and a female speaker A within the scenario is not explained by the content of the scenario.

It is also noted that the two main effects of higher ratings of conflict when females initiated conversations were found for the two vignettes in which the initiator begins to talk about money or the economy.

For scenario 3, a somewhat different gender effect was found. In that vignette, conflict was rated as more likely when either type of cross-sex dyad interacted, than when same-sex dyads talked. There may have been other effects, as well. There was a tendency for younger women (age 18-20) to rate conflict as more likely than older women rated it. It was the only scenario where a conversation began with a question, and the only scenario to mention clothing. 
Considering that the regression analysis showed different variables to relate to men's and women's ratings of potential conflict for scenario 3 , it appears that subjects interpreted the speakers differently. Men seemed to relate the likelihood of conflict to criticism by speaker $B$ and to an excessive demand by speaker $A$. Women seemed to consider the perception of an excessive demand by speaker A, and also $A^{\prime}$ s attempt to build consensus, met with a rebuff by speaker B. These effects were the expected ones according to the research hypothesis: that males would see potential conflict if they judged the speaker $A$ as making an excessive demand (an attempt to control the situation) and that females would see conflict as likely if they sensed rejection in the conversation.

The sole main effect for the variable of consensusbuilding by speaker $A$, in any scenario, was found for scenario 3. Males were rated as more likely to be trying to build consensus than were females in this conversation. The finding of highly rated potential conflict when a male was the initiating speaker may be an effect of a norm-violation: subjects may have found it odd for a male to begin a conversation about clothing and have his bid met with a lack of enthusiasm by a female. As Fishman (1983) noted, it is more common for topics initiated by women to be ignored. The results do not provide convincing support for Hypothesis 2, but neither do they provide evidence to 
reject the basic idea in the hypothesis. It is not possible to know how much of the variation in responses was an effect of scenario content, how much was due to the form of the conversations, nor how these variables interacted with the characteristics considered to be the independent variables for this study. A similar experiment could be done to try to identify some of these other effects of setting, activity, and format of conversation.

Two of the unexpected results which were obtained for relationships not specifically mentioned in the hypotheses are interesting, because they support some of the suggested explanations for gender variation in language which were noted in chapter II.

For example, Tannen (1990) asserts that women's conversation is oriented more to building consensus than is male conversation. Her contention is supported by the finding of a main effect for that variable. In scenario 1 , female subjects were more likely to interpret a speaker who initiated that conversation as attempting to build consensus, as measured by responses to the interpretation that "A wants to talk about packing and moving." It may be that this type of gender difference in interpreting conversation underlies everyday misunderstandings.

The second unexpected finding is intriguing. Effects of the gender of conversational partner in the dyad on interpretations of a speaker were found in two scenarios. 
In scenario 1, varying responses for speaker A's likelihood of speaking "directly" relates to whether speaker B is male or female; in scenario 2 , speaker $B^{\prime}$ s likelihood of being critical relates to the gender of speaker A. But these findings, though statistically significant, did not indicate trends for the effect for other variables. If language varies by the gender of the "spoken-to" partner, these results may be evidence of that variation. It may be a variable better studied by measuring subjects' interpretations of live or videotaped interactions. The majority of the dependent variables used for this study showed no significant relationships with the independent variables. Of the significant findings, some relationships may be spurious, such as the one finding of an effect of subject age. Some findings are interesting because they support theory and they would merit more investigation, such as the Hypothesis 1 findings indicating a greater understanding of male conversation by females than vice versa. This pattern was seen in only four out of forty analyses, which does not seem to be a large difference in the interpretations of conversations. On one hand, those findings may not mean much, but on the other hand, what if one out of every ten conversations is evaluated that way? If that were the case, Fishman's (1983) theory that women do a disproportionate amount of the "work" in conversations would be supported. 
Some findings are interesting because they indicate areas for further investigation, such as the Hypothesis 2 findings of a higher-rated likelihood of conflict for conversations initiated by females. This unexpected finding cannot be explained by this study, and merits further investigation.

Unger (1989) asserts, "Identical information involving gender roles is evaluated differently depending upon the sex of the stimulus person and the sex of the observer." This study found some support for that contention. Further research could look for effects of the sequence of remarks, as suggested by Holtgraves (1991); for variation by SES, education, ethnicity, etc., as suggested by spencer and Drass (1989); and for differences in the socialization of children, as recommended by Cicourel (1981).

It would be interesting to investigate the variation by subject gender found in this study. While this research found effects of subject gender for some dependendent variables, all subjects agreed highly on ratings of other variables. This agreement by subjects resulted in main effects for speaker's gender, or two-way interactions between the gender of both speakers. Kelley et al. (1978) found no variation by gender of subject when speakers in scenarios were evaluated, only variation by gender of speaker; Derlega and Chaikin (1976) had the same type of result. However, Garcia, Milano and Quijano (1989) obtained 
variation by gender of subject and by gender of speaker. Holtgraves (1991) found variation by subject gender for only one of the three variables in his study. (For this study, one of the items which did not vary in Holtgraves' research, the "direct interpretation" of a speaker, was chosen as a filler variable- and it elicited gender variation.)

Research investigating systematic gender differences in the interpretation of conversations could incorporate the nonverbal aspects of communication. Relatively little research has looked for differences in the interpretations of speech, compared to the amount of research done on the production of speech, and studies that have been carried out have tended to focus on the verbal channel. For example, an experiment using filmed speakers as stimulus material could be conducted, to study gender-related variation in interpretations of the verbal aspects of communication in conjunction with the nonverbal aspects. Results of such research could contribute to theory regarding gender, socialization, and communication, as well as having practical applications for relationships. 
REFERENCES

Adler, Max K. 1978. Sex Differences in Human Speech: A Sociolinguistic Study. Hamburg: Buske.

Argyle, Michael, Mansur Lalljee, and Mark Cook. 1968. "The Effects of Visibility in a Dyad." Human Relations $21: 3-17$.

Arliss, Laurie. 1991. Gender Communication. Englewood cliffs, N.J.: Prentice-Hall.

Baron, Dennis. 1986. Grammar and Gender. New Haven, Conn.: Yale University Press.

Bell, Amelia R. 1990. "Separate People: Speaking of Creek Men and Women." American Anthropologist $92: 332-45$.

Berger, Peter L., and Thomas Luckmann. 1966. The Social Construction of Reality. Garden City, N.Y.:

Doubleday.

Birdwhistell, Ray. 1970. "Masculinity and Femininity as Display." Chap. in Kinesics and Context: Essays on Body Motion Communication. Philadelphia, Penn.: University of Pennsylvania Press.

Black, Max. 1968. The Labyrinth of Language. New York: Mentor.

Bodine, Ann. 1975. "Sex Differentiation in Language." In Lanquage and Sex: Difference and Dominance, ed. Barrie Thorne and Nancy Henley. Rowley, Mass.: Newbury House.

Bolton, Charles D. 1980. "Mate Selection as the Development of a Relationship." In Marriage and the Family in a Changing Society, ed. James M. Henslin. New York: Free Press.

Borisoff, Deborah, and Lisa Merrill. 1985. The Power to Communicate: Gender Differences as Barriers. Prospect Heights, Ill.: Waveland Press.

Brown, Roger. 1986. Social Psychology, the second Edition. New York: Free Press. 
Bruschi, Irene G., and Beth Raymond. 1990. "What Women Think and What Men Think Women Think: Perceptions of Abuse and Kindness in Dating Relationships." Psychological Reports 67:115-28.

Cameron, Deborah. 1985. Feminism and Linguistic Theory. New York: st. Martin's Press.

Carli, Linda L. 1990. "Gender, Language and Influence." Journal of Personality and Social Psychology 59:941-51.

Chafetz, Janet Saltzman. 1988. Feminist sociology. Itasca, Ill.: F.E. Peacock.

Chesler, Phyllis. 1972. Women and Madness. Garden City, N.Y.: Doubleday.

Cicourel, Aaron V. 1981. "Notes on the Integration of Micro- and Macro-levels of Analysis." In Advances in Social Theory and Methodology: Toward an Integration of Micro- and Macro-Sociologies, ed. Karin D. Knorr-Cetina and Aaron V. Cicourel. Boston, Mass.: Routledge \& Kegan Paul.

Collins, Randall. 1981. "Micro-Translation as a TheoryBuilding strategy." In Advances in Social Theory and Methodology: Toward an Integration of Micro- and MacroSociologies, ed. Karin D. Knorr-Cetina and Aaron V. Cicourel. Boston, Mass.: Routledge \& Kegan Paul.

Coser, Lewis. A., ed. 1972. Sociology Through Literature. $2 d$ ed. Englewood Cliffs, N.J.: Prentice-Hall.

Crosby, Faye, Paul Jose, and William Wong-McCarthy. 1981. "Gender, Androgyny, and Conversational Assertiveness." In Gender and Nonverbal Behavior, ed. Clara Mayo and Nancy Henley. New York: Verlag.

Derlega, Valerian, and Alan L. Chaikin. 1976. "Norms Affecting Self Disclosure in Men and Women." Journal of Consulting and Clinical Psychology 44:376-80.

DuBois, Betty Lou, and Isabel Crouch. 1974. "The Question of Tag Questions in Women's Speech: They Don't Really Use More of Them, Do They?" Language in Society $4: 289-94$.

Eakins, Barbara W., and R. Gene Eakins. 1978. Sex Differences in Communication. Boston, Mass.: Houghton Mifflin. 
Edwards, Renee, James M. Honeycutt, and Kenneth S. Zagacki. 1989. "Sex Differences in Imagined Interactions." Sex Roles 21:263-72.

Fishman, Pamela M. 1983. "Interaction: The Work Women Do." In Language, Gender and Society, ed. Barrie Thorne and Nancy Henley. Rowley, Mass.: Newbury House.

Garcia, Luis, Laureen Milano, and Annette Quijano. 1989. "Perceptions of Coercive Sexual Behavior by Males and Females." Sex Roles 21:569-77.

Goffman, Erving. 1976. Gender Advertisements. New York: Harper Colophon.

- 1977. "The Arrangement Between the Sexes." Theory and Society 4:301-331.

- 1981. Forms of Talk. Pittsburgh, Pa.: University of Pennsylvania Press.

Gregerson, Edgar A. 1979. "Sexual Linguistics." In Language, Sex and Gender, Vol. 327, ed. Judith orasanu, Miriam K. Slater and Lenore L. Adler. New York: New York Academy of Sciences.

Greif, Esther B. 1980. "Sex Differences in Parent-Child Conversations." In The Voices and Words of Women and Men, ed. Cheris Kramarae. Oxford: Pergamon Press.

Haas, Adelaide. 1979. "The Acquisition of Genderlect." In Language, Sex and Gender, Vol. 327, ed. Judith Orasanu, Miriam K. Slater and Lenore L. Adler. New York: New York Academy of Sciences.

Henley, Nancy, and Barrie Thorne. 1975. He Said/She Said: An Annotated Bibliography of Sex Differences in Language, Speech and Nonverbal Communication. Pittsburg, Penn.: KNOW, Inc.

Holtgraves, Thomas. 1991. "Interpreting Questions and Replies: Effects of Face-Threat, Question Form, and Gender." Social Psychology Quarterly 54:15-24.

Joyce, James. 1962. [1916.] Dubliners. New York: Viking.

Kelley, Harold H., John D. Cunningham, Jill A. Grisham, Luc M. Lefebvre, Cathy Roberts Sink, and Gilbert Yablon. 1978. "Sex Differences in Comments Made During Conflict Within close Heterosexual Pairs." Sex Roles 4:473-92. 
Key, Mary Ritchie. 1975. Male/Female Language. Metuchen, N.J.: Scarecrow Press.

Komarovsky, Mirra. 1987. Blue-Collar Marriage. New Haven, Conn.: Yale University Press.

Kramer, Cheris. 1974. "Women's Speech: Separate But Unequal?" Quarterly Journal of Speech 60:14-24.

Kramarae, Cheris. 1982. "Gender: How She Speaks." In Attitudes Towards Language Variation, ed. Ellen B. Ryan and Howard Giles. London: Edward Arnold.

ed. 1980. The Voices and Words of Women and Men. Oxford: Pergamon Press.

Kramarae, Cheris, and Mercilee M. Jenkins. 1987. "Women Take Back the Talk." In Women and Language in Transition, ed. Joyce Penfield. Albany, N.Y.: State University of New York Press.

Lakoff, Robin. 1975. Lanquage and Woman's Place. New York: Harper Colophon.

1979. "Stylistic Strategies within a Grammar of Style." In Language, Sex and Gender, Vol. 327, ed. Judith Orasanu, Miriam K. Slater and Lenore L. Adler. New York: New York Academy of Sciences.

- 1990. Talking Power: The Politics of Lanquage in our Lives. New York: Basic Books.

Lee, Harper. 1960. To Kill a Mockingbird. New York: Popular Library.

Lewis, Helen B. 1976. "Intellectual Functioning." In Psychic War in Men and Women. New York: New York University Press.

Lowery, Carol R., C.R. Snyder, and Nancy W. Denney. 1976. "Perceived Aggression and Predicted Counteraggression as a Function of Sex of Dyad Participants: When Males and Females Exchange Verbal Blows." Sex Roles $2: 339-46$.

Marwell, Gerald and David R. Schmitt. n.d. "Child-Rearing Experience and Attitudes Toward the Use of Influence Techniques." Unpublished paper, Department of Sociology, University of Wisconsin.

Maynard, Joyce. 1981. Baby Love. New York: Knopf. 
Mayo, Clara, and Nancy Henley, eds. 1981. Gender and Nonverbal Behavior. New York: Verlag.

McClintock, Evie. 1983. "Interaction." In close

Relationships, ed. Harold H. Kelley, Ellen Berscheid, Andrew Christensen, John H. Harvey, Ted L. Huston, George Levinger, Evie McClintock, Letitia Anne Peplau and Donald R. Peterson. New York: Freeman and Co.

Medicine, Bea. 1987. "The Role of the American Indian Women in Cultural Continuity and Transition." In Women and Lanquage in Transition, ed. Joyce Penfield. Albany, N.Y.: State University of New York Press.

Michener, James A. 1949. The Fires of Spring. New York: Bantam.

Mills, C. Wright. 1959. The Sociological Imagination. New York: Grove Press.

Parker, Dorothy. 1944. The Portable Dorothy Parker. New York: Viking.

Peterson, Donald R. 1983. "Conflict." In Close Relationships, ed. Harold H. Kelley, Ellen Berscheid, Andrew Christensen, John H. Harvey, Ted L. Huston, George Levinger, Evie McClintock, Letitia Anne Peplau and Donald R. Peterson. New York: Freeman and Co.

Philips, Susan U., Susan Steele, and Christine Tanz, eds. 1987. Language, Sex and Gender in Comparative Perspective. New York: Cambridge University Press.

Scott, Kathryn P. 1980. "Perceptions of Communication Competence: What's Good for the Goose is Not Good for the Gander." In The Voices and Words of Women and Men, ed. Cheris Kramarae. Oxford: Pergamon Press.

Simkins-Bullock, Jennifer A., and Beth G. Wildman. 1991. "An Investigation into the Relationships Between Gender and Language." Sex Roles 24:149-60.

Smith, Philip M. 1985. Lanquage, the sexes and Society. New York: Basil Blackwell.

Speier, Matthew. 1973. How to Observe Face-to-Face Communication: A Sociological Introduction. Pacific Palisades, Cal.: Goodyear Publishing.

Spencer, J.W., and K. A. Drass. 1989. "The Transformation of Gender into Conversational Advantage: A Symbolic Interactionist Approach." Soc. Quarterly 30:363-83. 
Stewart, Lea P., Pamela J. Cooper, and Sheryl A. Friedley. 1986. Communication Between the Sexes: Sex

Differences and Sex-Role stereotypes. Scottsdale, Ariz.: Gorsuch Scarisbrick.

Tannen, Deborah. 1990. You Just Don't Understand: Women and Men in Conversation. New York: Morrow.

Thorne, Barrie, and Nancy Henley, eds. 1975. Lanquage and Sex: Difference and Dominance. Rowley, Mass.: Newbury House.

Thorne, Barrie, Cheris Kramarae, and Nancy Henley, eds. 1983. Language, Gender and Society. Rowley, Mass.: Newbury House.

Tolstoy, Leo. 1961. [1877.] Anna Karenina. New York: signet.

Turner, Ralph. 1970. Family Interaction. New York: John wiley.

Unger, Rhoda K., ed. 1989. Representations: Social Constructions of Gender. Amityville, N.Y.: Baywood.

Updike, John. 1959. The Same Door. New York: Fawcett.

Warner, M. 1989. "Out of the Mouths of Wimmin." New Statesman Society 2 (Nov.17):30-2.

West, Candace, and Don H. Zimmerman. 1987. "Doing Gender." Gender and Society 1:125-51.

Wilmot, William w. 1987. Dyadic communication. 3d ed. New York: Random House.

Zentella, Ana Celia. 1987. "Language and Female Identity in the Puerto Rican Community." In Women and Language in Transition, ed. Joyce Penfield. Albany, N.Y.: State University of New York Press.

Zimmerman, Don H. and Candace West. 1975. "Sex Roles, Interruptions and Silences in conversation." In Language and Sex: Difference and Dominance, ed. Barrie Thorne and Nancy Henley. Rowley, Mass.: Newbury House. 
APPENDIX A

SAMPLE STIMULUS BOOKLET 


\title{
APPENDIX A \\ SAMPLE STIMULUS BOOKLET
}

\author{
CONVERSATION QUESTIONNAIRE
}

I ar studying some of the ways people talk to each other, and $I$ am interested in your opinions. Your voluntary participation is appreciated.

This study is being done for my graduate research, and the results may be helpful to other people.

Please do NOT write your name on this questionnaire. It will be completely anonymous. Your participation will not affect your grades in any way.

If you don't understand part of the questionnaire, please do the best you can. There can be no discussion of it.

You may contact me if you would like further information about this study.

Thank you for your time. It is appreciated.

Constance M. Cooper

Graduate Student

Department of Sociology

Portland State University

Please answer the questions in the order in which they appear. You will be asked to rate your opinions about several statements, using a 0 -to-5 scale.

For example, consider: "This room was cleaned yesterday."

If you think this is NOT at all likely to be true, how would you mark the rating scale?

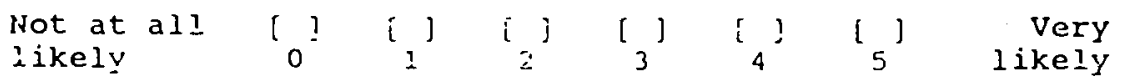

But if you think "This roon was cleaned yesterday" Is highly likely to be accurate, how would you mark the rating scale?

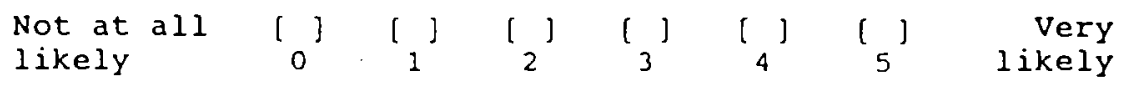


story 1.

Kathy and Tina are helping a friend move to a ney apartwent. Wh1le their friand goes out to get pizza, Kathy and Tina are packing booke into boxes.

KATHY: "There are et111 a lot of books left to pack."

TINA: "I know."

KATHY: Wwe don't have enough boxes, do we?"

ITHA: "Yes, ve do."

Now, thinking of how you interpret this conversation,

rate each of the follouing explanations for what $\mathrm{BATHY}$ says:

Kathy expecta Tina to go get more boxes.

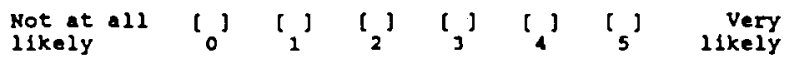

Kathy $1 \mathrm{~s}$ criticling Tina for not getting enough boxes in the first place.

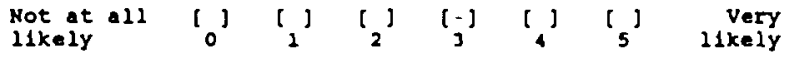

Kathy vants to get Tina to talk about packing and moving.

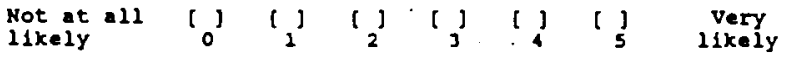

Kathy vants Tina to decide what to do next.

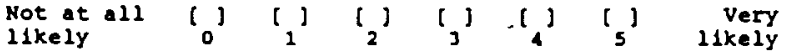

Kathy really can't tall if there are enough boxes.

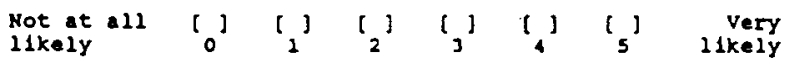

again, thinking of hou you would interpret this conversation, rate each of the follouing explanations for what IINA says:

Tina ia refusing to discuss the situation.

$\begin{array}{llllllll}\text { Not at all } & \left.[]_{0}\right] & \left.[]_{1}\right] & \left.[]_{2}\right] & {[]_{3}} & {[]_{4}} & {[5]} & \text { Very }\end{array}$

Tina 1a criticizing Kathy for asking about the boxea.

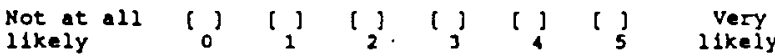

Tina is encouraging Kathy to talk about packing and moving.

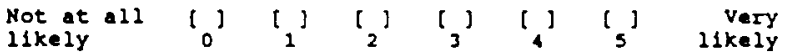

Tina ie elguring out a way to finish packing all the books.

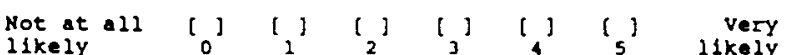

Tina has counted the boxes and knows there are enough.

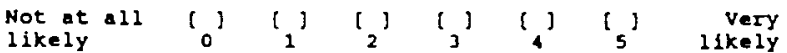

Now, rate hou much you predict that these two people alght end up hdving an argument, ilght, or other conflict because of this conversation.

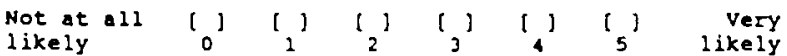


Story 2 .

Jenny and Dave are on their way back from a trip to the beach. The car doesn't have a tape player, and they're too far up in the mountaina to lieten to the radio.

JENNY: "Looke like the country' In a bad recession." DAVE: "Yeah."

IENNY: "If the economy keeps going downhlil, my job' going to be on the line. I hope I don't get laid off." DAYE: $\mathrm{Hm}$.

Now, thinking of hou you interpret this conversation. rate each of the following axplanations for what JaNDY aya:

Jenny ie criticizing Dave, because Dave doesn't inderstand economic issues.

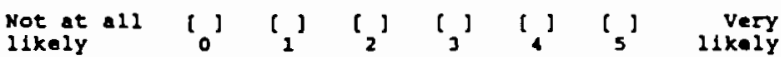

Jenny vould Iike Dave to decide what Jenny should do about her job.

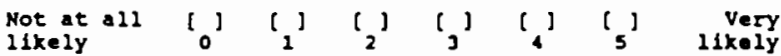

Jenny is trying to get Dave to talk, when Dave obviously doen't want to.

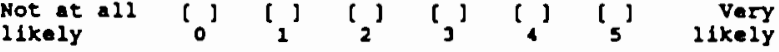

Jenny is "thinking out loud" and doean't expect Dave to anwur.

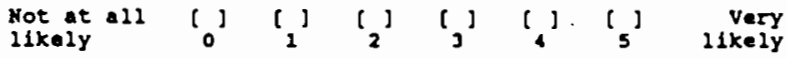

Jenny wante Dave to talk about jobs and other problems.

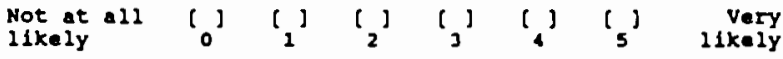

Again, thinking of hou you interprat this conversation, rate each of the following explanations for what Days eays:

Dave is criticlzing Jenny because Jenny is rrong about the economic iscues.

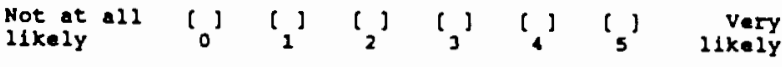

Dave 1s trying to decide what Jenny ahould do about her job.

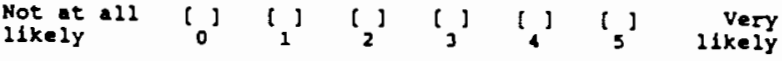

Dave is not paying attention to Jenny.

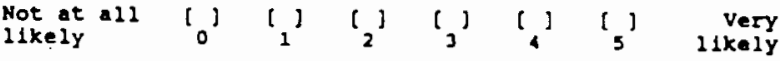

Dave agrees with Jenny.

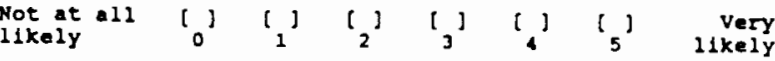
Dave is glad to have a chance to talk about jobs and other
problems.

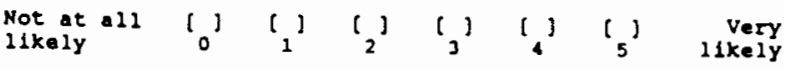

Now, rate hou much you predlct that these two people might end up having an argument, fight, or other conflict because of this conversation.

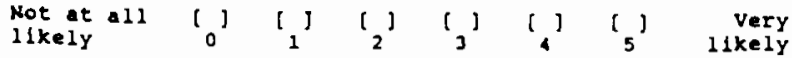


story 3.

Bob and Roger meet at a restaurant for lunch. After placing their food orders, Bob gets out a page torn from a wagazine. It is an advertisement for a jacket.

BOB: "I'm thinking of getting thle jacket. What do you think?" ROGER: "It's okay."

BOB: "I can't decide if lt looks right for me."

BOGEB: "Get it if you like it."

Now, thinking of how you interpret this convereation, rate each of the following explanatione for what BOB cays:

Bob is asking Roger to ake the decletion about getting the jacket.

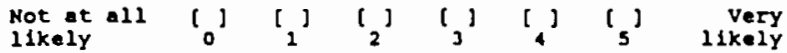

Bob wants to Involve Roger in a discusaion about the jacket.

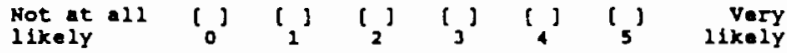

Bob wanta to keep thinking about the jacket.

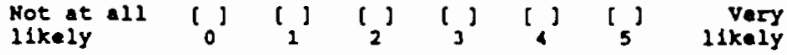

Bob is criticizing Roger, because Roger doesn't know enough about clothes.

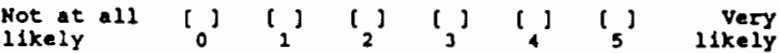

Bob is pushing Roger Into looking at the plcture, when Roger clearly is not interested.

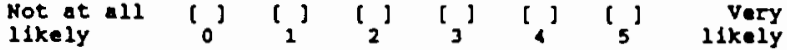

Again, thinking of how you interpret this converation, rate each of the following explanations for wat Bogms says:

Roger has decided that Bob should get the jacket.

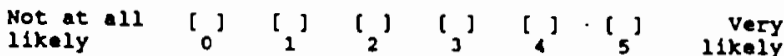

Roger would like to keep on discussing the jacket.

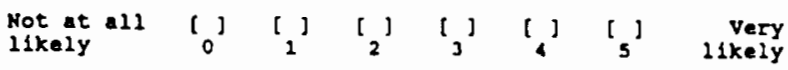

Roger wants Bob to make up hil own mind.

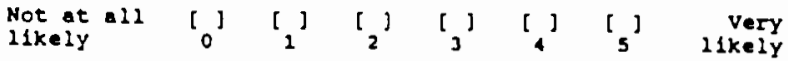

Roger is criticizing Bob's taste in clothes.

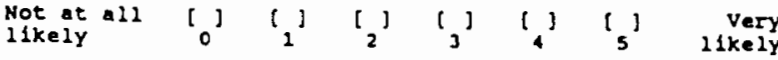

Roger is not really listening to Bob.

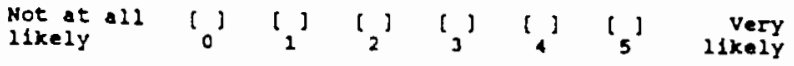

Now, rate how wuch you predict that these two people alght end up having an argument, flght, or other conflict becauae of

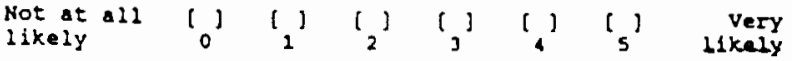


Story 4.

Andy and J111 are on their vay to cee a movie.

ANDY: "I hope ve've got enough money."

IILL: "The ticket. ere only three doilara each."

SNDY: "No, that's not what I meant. I mean, I hope va've got

enough money to get popcorn and something to drink, too."

JLL: "I'm not vorried about it."

Now, thinking of hov you yould interpret this conversation, $r$ t. each of the following explanations for what aNDY says: Andy vante to talk about what kinds of refreshmente they $\mathbf{m i g h t}$ get
at the theatre.

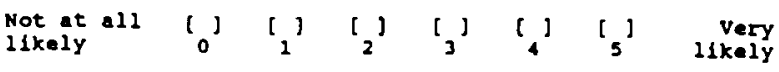

Andy is worried about money.

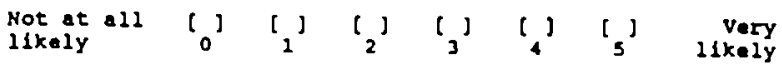

Andy vants Jill to make the decleion about whether or not they have enough zoney.

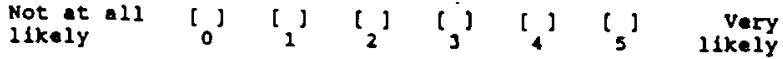

Andy is trying to get J11l to pay for too wuch.

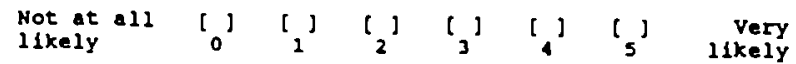

Andy is hinting that J11l should have underetood what he meant, vithout having to explain 1 t.

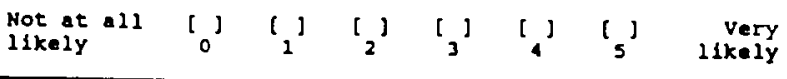

Again, thinking of how you would interpret this conversation. rate each of the following explanations for what JILL says: J11 wanta to keep on discusaing what refreshments they alght get
at the theotre.

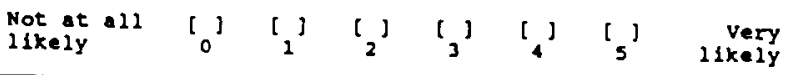

J11 is not vorried about money.

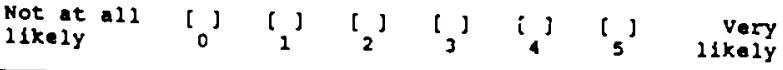

J11 has decided that they have enough money.

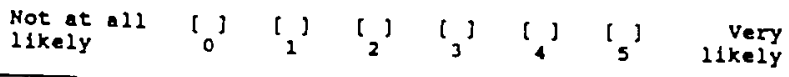

Jil von't talk about Andy's concerne.

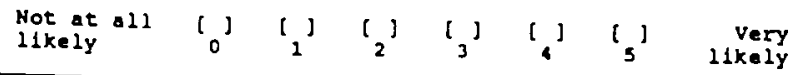
Jill thinke that it is stupid for Andy to bring up the topic of
money.

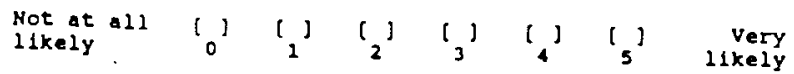

Now, rate how wuch you predict that these two people might end up having an argument, fight, or other conflict because of thia conversation.

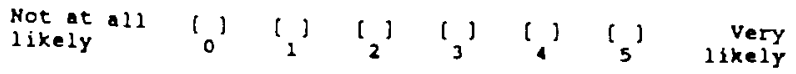


DEMOGRAPHICS

(1) Are you male? [_] or are you female? [_]

(2) What is your age? [__ ]

(3) Is English your native language? yes [_] no [_]

(4) What is your major at PSU? (If you haven't decided, what are you thinking of choosing as your major?)

$[+]$

Thank you for your time and your opinions in this study. 


\section{APPENDIX B}

\section{SPEAKERS' NAMES FOR}

STIMULUS BOOKLET 
APPENDIX B

SPEAKERS' NAMES FOR

STIMULUS BOOKLET

FEMALE SPEAKER

MALE SPEAKER

FOR SCENARIO 1

SPEAKER A

KATHY

KEVIN

SPEAKER B

TINA

TIM

FOR SCENARIO 2

SPEAKER A

JENNY

JEFF

SPEAKER B

DAWN

DAVE

FOR SCENARIO 3

SPEAKER A

BETH

BOB

SPEAKER B

RHONDA

ROGER

FOR SCENARIO 4

SPEAKER A

ANNE

ANDY

SPEAKER B

JILL

JIM 